\title{
Impact of temperature field inhomogeneities on the retrieval of atmospheric species from MIPAS IR limb emission spectra
}

\author{
M. Kiefer ${ }^{1}$, E. Arnone ${ }^{2}$, A. Dudhia ${ }^{3}$, M. Carlotti ${ }^{2}$, E. Castelli ${ }^{4}$, T. von Clarmann ${ }^{1}$, B. M. Dinelli ${ }^{4}$, A. Kleinert ${ }^{1}$, \\ A. Linden ${ }^{1}$, M. Milz ${ }^{1, *}$, E. Papandrea ${ }^{2}$, and G. Stiller ${ }^{1}$ \\ ${ }^{1}$ Karlsruhe Institute of Technology, Institute for Meteorology and Climate Research, Karlsruhe, Germany \\ ${ }^{2}$ Dip. to di Chimica Fisica e Inorganica, Universitá di Bologna, Italy \\ ${ }^{3}$ University of Oxford, AOPP, Oxford, UK \\ ${ }^{4}$ ISAC-CNR - Istituto di Scienze dell'Atmosfera e del Clima - CNR, Bologna, Italy \\ * now at: Department of Space Science, Luleå University of Technology, Kiruna, Sweden
}

Received: 22 March 2010 - Published in Atmos. Meas. Tech. Discuss.: 14 April 2010

Revised: 18 October 2010 - Accepted: 25 October 2010 - Published: 29 October 2010

\begin{abstract}
We examine volume mixing ratios (vmr) retrieved from limb emission spectra recorded with the Michelson Interferometer for Passive Atmospheric Sounding (MIPAS) on board Envisat. In level 2 (L2) data products of three different retrieval processors, which perform one dimensional (1-D) retrievals, we find significant differences between species' profiles from ascending and descending orbit parts. The relative differences vary systematically with time of the year, latitude, and altitude. In the lower stratosphere their monthly means can reach maxima of $20 \%$ for CFC-11, CFC-12, $\mathrm{HNO}_{3}, \mathrm{H}_{2} \mathrm{O}, 10 \%$ for $\mathrm{CH}_{4}$ and $\mathrm{N}_{2} \mathrm{O}$. Relative differences between monthly means of 1-D retrieval results and of the true atmospheric state can be expected to reach half of these percentage values, while relative differences in single vmr profiles might well exceed those numbers. Often there are no physical or chemical reasons for these differences, so they are an indicator for a problem in the data processing. The differences are generally largest at locations where the meridional temperature gradient of the atmosphere is strong. On the contrary, when performing the retrieval with a tomographic two dimensional (2-D) retrieval, L2 products generally do not show these differences. This suggests that inhomogeneities in the temperature field, and possibly in the species' fields, which are accounted for in the 2-D algorithm and not in standard 1-D processors, may cause significant deviations in the results. Inclusion of an externally given adequate temperature gradient in the forward model of a 1-D processor helps to reduce the observed differences. However, only the full tomographic 2-D approach is suitable to resolve the horizontal inhomogeneities. Implications for the
\end{abstract}

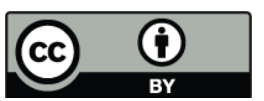

Correspondence to: M. Kiefer (michael.kiefer@kit.edu) use of the 1-D data, e.g. for validation, are discussed. The dependence of the ascending/descending differences on the observation strategy suggests that this problem may affect 1$D$ retrievals of infrared limb sounders, if the line of sight of the instrument has a significant component in the direction of the horizontal temperature variation.

\section{Introduction}

\subsection{MIPAS on Envisat}

MIPAS, the Michelson Interferometer for Passive Atmospheric Sounding, is a mid-infrared Fourier-transform spectrometer which is part of the core payload of Envisat (Fischer et al., 2000, 2008). Envisat is on a sun-synchronous near polar orbit at $800 \mathrm{~km}$ altitude (14.4 orbits per day) with the descending node crossing at 10:00 MST (mean solar time).

MIPAS scans the atmosphere vertically in limb geometry detecting atmospheric thermal radiation from the middle atmosphere and upper troposphere. The instrument has the advantages common to IR limb emission sounders, namely (a) good sensitivity due to collecting photons along a long line of sight, (b) good vertical resolution, since the majority of the signal is emitted close to the tangent point, (c) independence on external radiation sources, which means that measurements during day and night, especially important during polar night, can be performed. Because of the platform's longitude drift MIPAS measures limb radiance spectra of a certain region on Earth with approximately $12 \mathrm{~h}$ difference with the dayside data being measured during the descending and the nightside data during the ascending part of the orbit.

Published by Copernicus Publications on behalf of the European Geosciences Union. 
MIPAS is installed at the rear of Envisat, looking essentially backwards with respect to the satellite's flight direction in the nominal observation mode. To get a better latitude coverage the line of sight's azimuth is commanded to the poleward side of the flight path around the poles. These azimuth deviations with respect to the backwards direction are $20^{\circ}$ at the North Pole and $15^{\circ}$ at the South Pole. Between the polar regions there is a smooth transition over this azimuth difference of $35^{\circ}$. In summary this means that during the descending part of the orbit the instrument essentially looks northward, while during the ascending part it essentially looks southward.

\subsection{Motivation}

A first hint that there are problems in some MIPAS retrieval results was discovered by Höpfner et al. (2007). In that work several species retrieved with the IMK/IAA level 2 processor (von Clarmann et al., 2003b) were compared to measurements of ACE-FTS (Bernath, 1999; Bernath et al., 2005). A separation of data with respect to day/night conditions was performed. Notably in CFC-11 there was a clear influence of whether day or night data of IMK/IAA were chosen (see Figs. 6 and 7 of Höpfner et al., 2007). MIPAS daytime values were by about $10 \%$ higher than their nighttime counterparts. CFC-12 also showed a day/night difference, albeit with a magnitude of 5-10\% somewhat less pronounced (see Fig. 8 ibid.). Since ACE data was not separated accordingly (there is occultation data for sunrise and sunset data, but only the latter one had been used for the comparison) but rather remained unchanged, the conclusion was that there is an anomaly in the version of MIPAS CFC-11 and CFC12 data adopted for the comparison (IMK/IAA data versions V3O_F-11_8 and V3O_F-12_9).

For most latitudes, MIPAS measurements for day and night correspond to northward and southward directions of the line of sight, respectively (see Sect. 1.1). Therefore at a given location the atmosphere with all its inhomogeneities is seen by the instrument from the north for night and from the south for day measurements. Now, if there were an influence of the direction of the line of sight with respect to an atmospheric feature, one could expect to see this influence in a difference between MIPAS day and night data.

Although e.g. Livesey and Read (2000) for Aura/MLS and Carlotti et al. (2001, 2006) and Steck et al. (2005) for MIPAS discussed the advantages of being able to model the inhomogeneity along the line of sight in the retrieval of atmospheric data, no systematic assessment of shortages in results from level 2 processors relying upon the assumption of a horizontal homogeneous atmosphere was performed up to now.

These shortages, together with the different assumption adopted by $1-\mathrm{D}$ and $2-\mathrm{D}$ retrievals, motivates the thorough analysis of the impact of temperature inhomogeneity on the retrieval results presented in this paper.

\section{Processing of MIPAS data}

\subsection{Level 1b processing}

The level $1 \mathrm{~b}$ processing, i.e. the generation of geolocated and radiometrically calibrated mid IR limb radiance spectra from the instrument's detectors output is done exclusively by ESA. A detailed description of the procedure can be found in Kleinert et al. (2007). All of the level 2 processors described in the following use the level $1 \mathrm{~b}$ data of this same source.

\subsection{Level 2 processing}

Level 2 (L2) data, i.e. the geolocated atmospheric physical and chemical quantities derived from level $1 \mathrm{~b}$ spectra, are estimated by fitting synthetic spectra, produced with radiative transfer models, to the observations. In this work we consider 1-D and 2-D retrievals of MIPAS data. Here the term 1-D retrieval is used for retrievals where, based on the fact that the bulk of information comes from the region close to the tangent height, the atmosphere is assumed to be horizontally homogeneous with respect to mixing ratios of constituents and to temperature and pressure. In 2-D retrievals the atmospheric state is allowed to vary also in the horizontal (Carlotti et al., 2001; Steck et al., 2005). The assumption of horizontal homogeneity fails in presence of e.g. strong horizontal gradients, which are modelled in the 2-D approach by a simultaneous fit of the complete orbit.

A common feature of all 1-D processors considered here and the 2-D processor is that only small parts of the measured spectrum, so-called microwindows, which depend on retrieval target and altitude, are used (von Clarmann and Echle, 1998; Dudhia et al., 2002). The spectral positions and extents of the microwindows might differ between the processors, depending on the retrieval target. Some details of the adopted 1-D and 2-D retrievals are briefly summarized hereafter.

In this paper we present data of three different 1-D MIPAS L2 retrieval processors, namely the ESA offline processor (data designated ESA), the University of Oxford MORSE processor (data designated Oxford), and the IMK/IAA processor (designation IMK/IAA). All these processors retrieve temperature and trace gas abundances by inversely modeling radiative transfer such that the modeled spectra fit optimally to the measured ones according to a quadratic cost function. To cope with the non-linearity of radiative transfer, all retrieval processors involve Newtonean iteration.

The analysis starts with spectral windows containing mainly $\mathrm{CO}_{2}$ lines, from which the temperature profile and elevation pointing information of the instrument are retrieved. In subsequent steps, profiles of mixing ratios of trace gases are retrieved, whereby temperature and pointing information retrieved in the preceding step are used. This implies that any error in the result of the first processing step, i.e. the retrieval of the temperature profile, will propagate into the species 

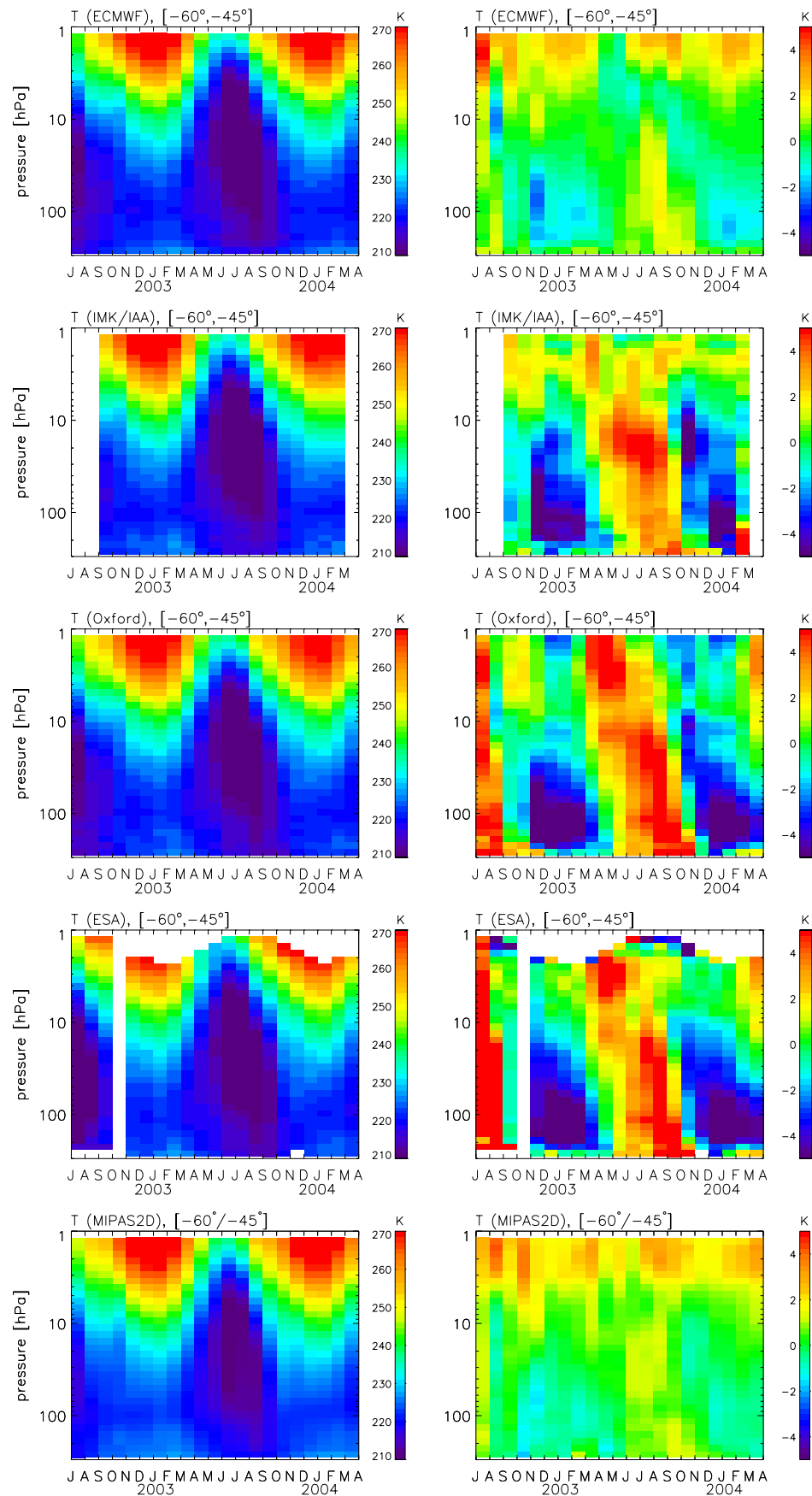

Fig. 1. Distribution of monthly means of temperature (left column) and ascending/descending temperature differences (ascending minus descending, right column) for ECMWF reanalysis data (top row), 1-D retrievals (second row: IMK/IAA, third row: Oxford, fourth: ESA), and 2-D retrieval (MIPAS2-D, bottom row) over time and pressure. Data is shown for the latitude range $60^{\circ} \mathrm{S}$ to $45^{\circ} \mathrm{S}$. Tick marks of the time axis give the begin of months.

profiles' retrievals. Besides the target quantities (temperature, mixing ratios) these retrieval codes also retrieve an empirical atmospheric continuum and an additive radiance calibration correction, for reasons extensively discussed in von Clarmann et al. (2003b).
The differences between these retrieval codes are mainly related to the forward radiative transfer model used, the simultaneous versus sequential analysis of the spectra of one limb sequence of measurements, the microwindows selected, the choice of the constraint, the discretization of the atmosphere and the representation of the retrieved profiles, the 

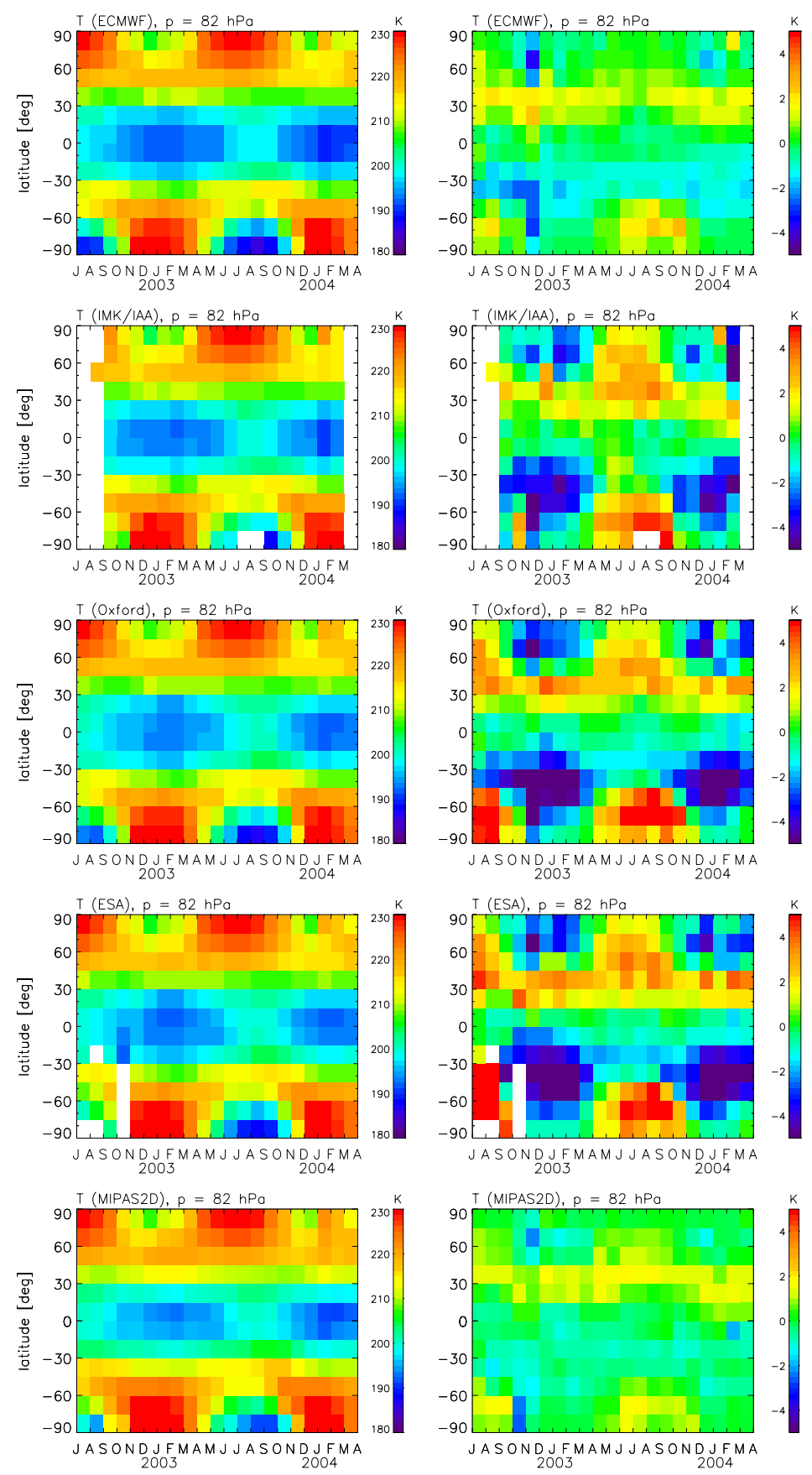

Fig. 2. Distribution of monthly means of temperature (left column) and ascending/descending temperature differences (right) for ECMWF reanalysis data (top row), 1-D retrievals (second row: IMK/IAA, third row: Oxford, fourth: ESA), and 2-D retrieval (MIPAS2-D, bottom row) over time and latitude on the $82 \mathrm{hPa}$ pressure level. Latitude bins are $15^{\circ}$. Tick marks of the time axis give the begin of months.

treatment of interfering species in trace gas retrievals, and the criteria for rejection of cloud-contaminated spectra.

All involved radiative transfer models have been extensively cross-checked (von Clarmann et al., 2002, 2003c), and two of the retrieval codes used here, the ESA Offline L2 processor and the IMK/IAA L2 processor, have been validated in a blind test retrieval exercise (von Clarmann et al., 2003a).
In the following, we shortly summarize the specific characteristics of the retrieval processors used here.

\subsubsection{ESA Offline L2 processor}

The ESA Offline L2 processor uses the OFM (Optimized Forward Model) Ridolfi et al. (2000) for radiative transfer 

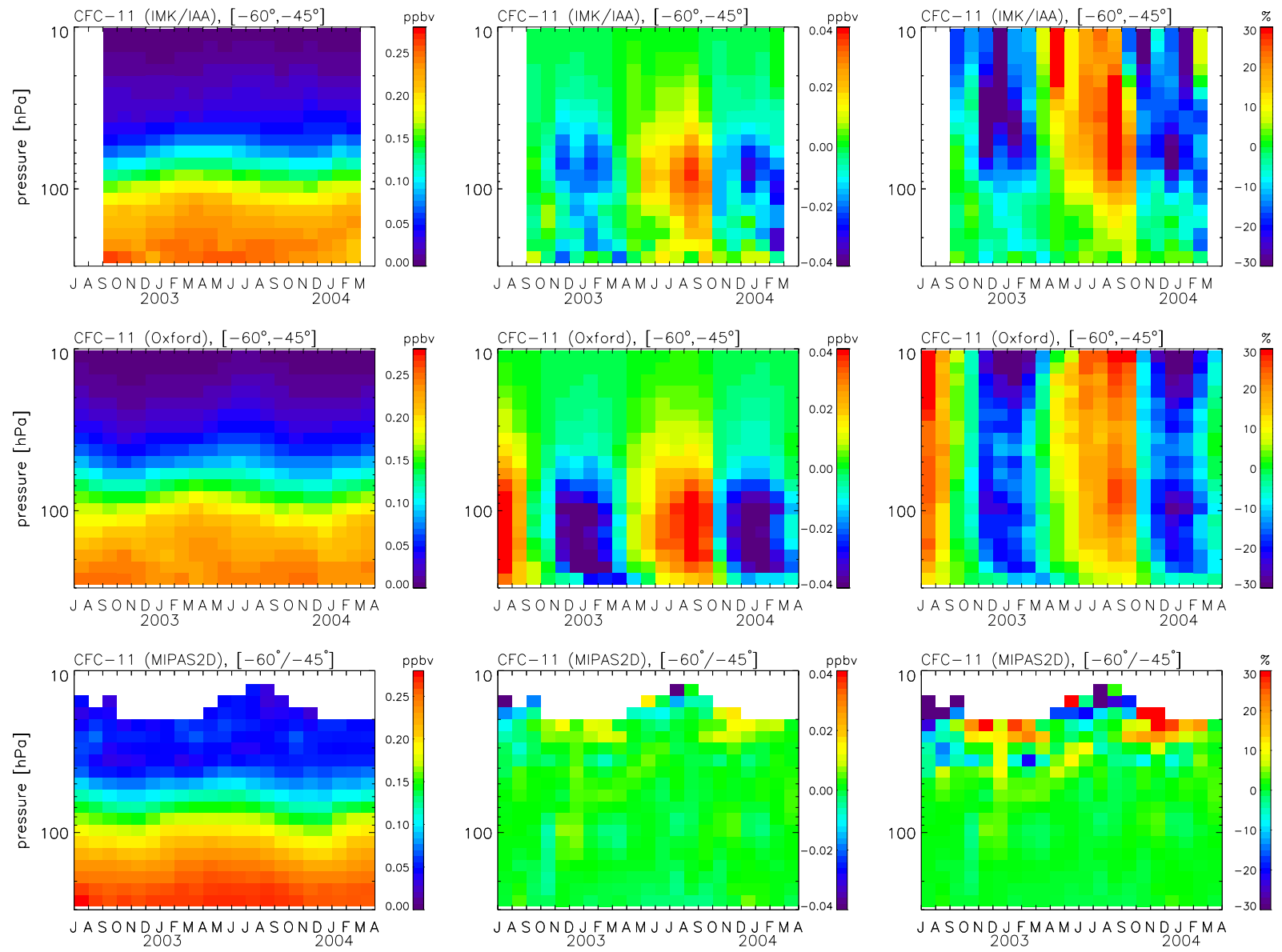

Fig. 3. Distribution of average values of CFC-11 (left column), of ascending/descending differences (middle column), and relative differences (right) for 1-D retrievals (top row: IMK/IAA, middle row: Oxford) and for 2-D retrievals (MIPAS2-D, bottom row). Time bin is one month, latitude bin is $60^{\circ} \mathrm{S}$ to $45^{\circ} \mathrm{S}$. Altitude bins for 1-D and 2-D data are explained in Sect. 3.1. The tick marks of the time axis give the begin of the months and years, respectively.

calculation; the retrieval is based on unconstrained least squares fitting of modeled to measured radiances. Spectra of a limb sequence of measurements are analyzed in one step rather than sequentially, following the so-called "global-fit" approach (Carlotti, 1988). The iteration is started with initial guess values taken from a climatology by Remedios et al. (2007). The grid on which retrieved profiles are sampled is given by the tangent altitudes of the measurements. In a first step, temperature, pressure at the tangent altitude, and pointing correction with respect to tangent altitude separation are retrieved. This information is passed on to the trace gas retrievals. These are performed separately and independently for each species, using climatological information for interfering species. Spectral microwindows are selected using the methodology developed by Dudhia et al. (2002). Further details of this processor are reported in Raspollini et al. (2006).

\subsubsection{Oxford University L2 processor}

The Oxford L2 processor, MORSE (MIPAS Orbital Retrievals using Sequential Estimation, documentation at http: //www.atm.ox.ac.uk/MORSE/) mainly differs from the ESA processor in using optimal estimation (Rodgers, 2000) rather than an unregularized least squares fit approach. The optimal estimation provides certain advantages in numerical stability, at the risk of biasing the retrieval towards the a priori in case of insufficient measurement information, and the sequential aspect allows memory usage to be minimised (at the expense of increased CPU time), effectively by incorporating measurements from just one microwindow/tangent altitude at a time rather than all simultaneously.

It uses the same microwindows and absorption coefficient look-up tables as the ESA processor, and additionally retrieves CFC-11, CFC-12, $\mathrm{N}_{2} \mathrm{O}_{5}$ and $\mathrm{ClONO}_{2}$.

The internal forward model is based on the RFM (Reference Forward Model, http://www.atm.ox.ac.uk/RFM) but 

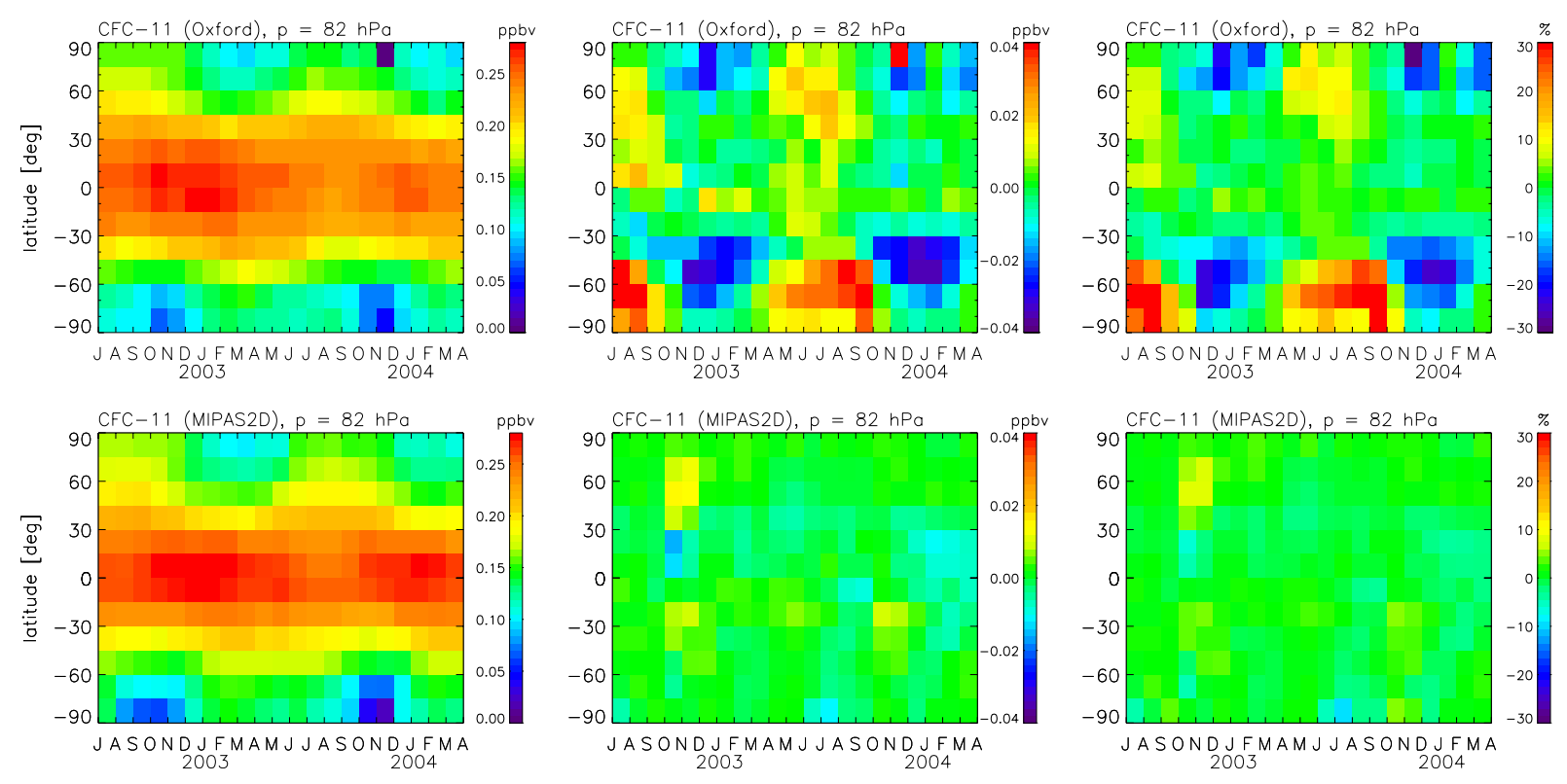

Fig. 4. Distribution of mean values of CFC-11 vmr (left column), ascending/descending differences (middle column), and relative differences (right) for Oxford 1-D (top row) and Bologna MIPAS2-D (bottom row) retrievals. Time bin is one month, latitude bin is $15^{\circ}$, pressure is $82 \mathrm{hPa}$.

using the pretabulated monochromatic absorption coefficients rather than a full line-by-line calculation.

The a priori estimates required for the optimal estimation approach are taken from the climatology of Remedios et al. (2007) (which also provides the initial guess for the ESA retrievals). These do not distinguish between day and night or longitude, so the a priori estimates used at a particular latitude are identical for the ascending and descending passes within any one day.

\subsubsection{IMK/IAA Scientific L2 processor}

The retrieval strategy employed in the IMK/IAA L2 processor has been extensively discussed by von Clarmann et al. (2003b). As with the ESA Offline L2 processor, measurements at all tangent altitudes are analyzed in one step rather than sequentially, but contrary to the global-fit approach, the retrieved atmospheric state variables are represented on a fixed altitude grid rather than on a grid defined by the tangent altitudes, and the cost function involves a constraint. This regularization of the least squares fit is a Tikhonov-type first-order smoothing constraint for temperature and volume mixing ratios. The sequence of analyses of species is chosen such that error propagation is minimised. Multiple target retrievals are performed whenever necessary to avoid propagation of errors due to uncertain parameters.

For the bulk of IMK/IAA data presented here, the atmosphere is assumed to be horizontally homogeneous with respect to temperature and mixing ratios of constituents. Data of data versions V3O_T_8, V3O_F-11_8 and V3O_HNO3_7 presented here were retrieved with the 1-D version of the IMK/IAA processor.

However, the L2 processor is capable of taking into account some properties of a horizontally inhomogeneous atmosphere, e.g. the inclusion in the forward model of externally given gradients of temperature and/or species, together with a proper length scale. A more sophisticated method, namely the retrieval of temperature gradients, constrained by a priori information from ECMWF data, is routinely used for more recent IMK/IAA retrievals, e.g. for the L2 data of reduced resolution spectra for MIPAS data from 2005 on (von Clarmann et al., 2009b). The retrieval of horizontal vmr gradients is routinely employed in the $\mathrm{L} 2$ processing of $\mathrm{NO}$, $\mathrm{NO}_{2}$, and $\mathrm{CO}$ (Funke et al., 2009).

\subsection{2-D retrieval}

Two-dimensional retrievals have been operated with the GMTR (Geofit Multi-Target Retrieval) analysis system fully described in Carlotti et al. (2006). GMTR was developed as an open source code, specifically designed for MIPAS measurements, delivered to ESA and included in the BEAT tools repository (http://envisat.esa.int/services/beat). The upgraded version 2.1 of GMTR was used to generate the MIPAS2-D database of level 2 products used in this paper (Papandrea et al., 2010; Dinelli et al., 2010).

Version 2.1 of GMTR can be exploited for the analysis of all the MIPAS observation scenarios and includes the possibility of performing retrievals using the Optimal Estimation method (Rodgers, 2000). This new functionality was introduced to better handle measurements affected by clouds in 

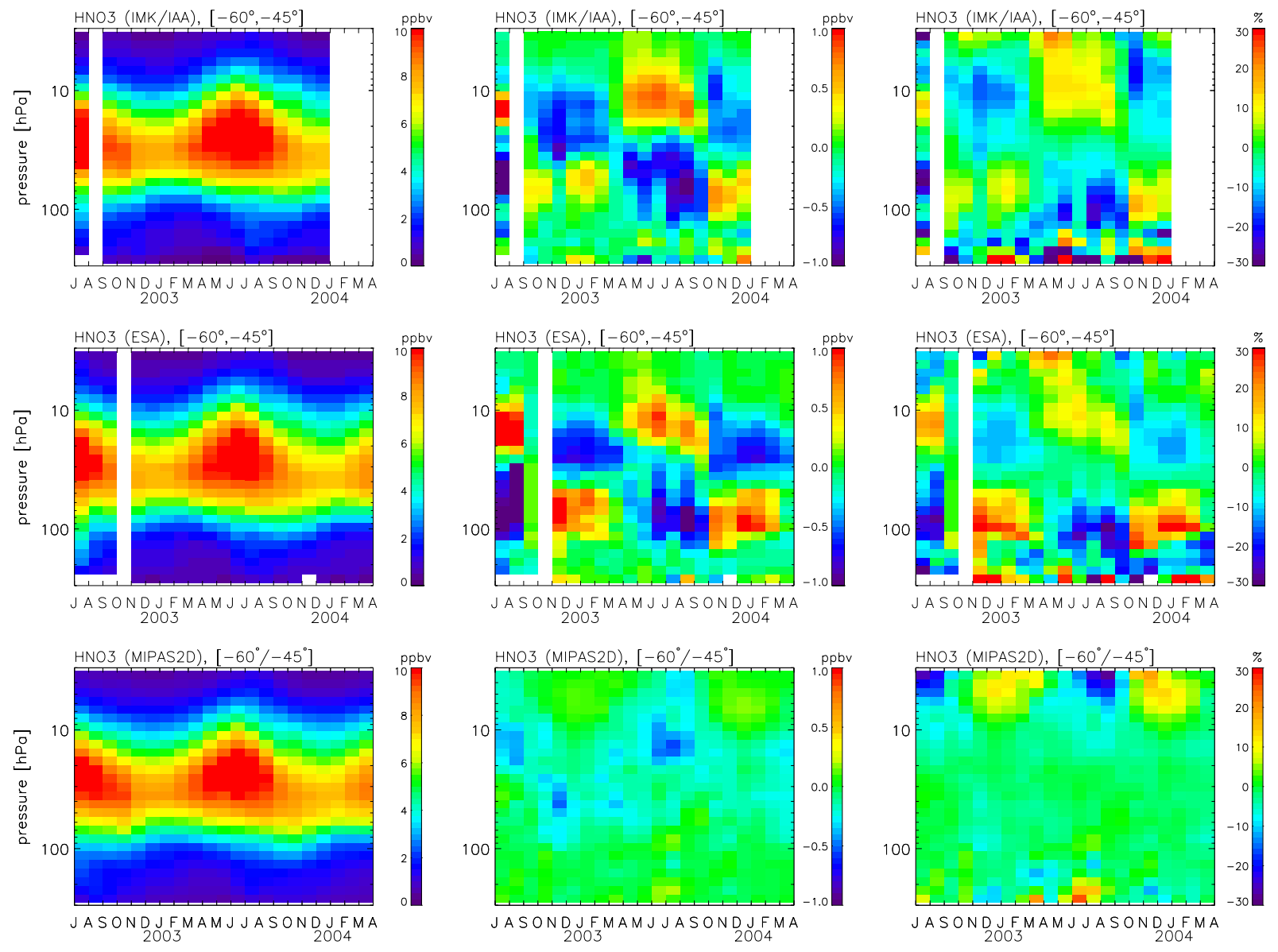

Fig. 5. Same as Fig. 3, but for $\mathrm{HNO}_{3}$ of IMK (top) and ESA 1-D (middle) and MIPAS2-D (bottom) retrievals.

the line of sight, and to cope with the limb-scanning pattern that changes with latitude.

The GMTR analysis system is based on the Geo-fit approach (Carlotti et al., 2001) upgraded with the Multi-Target Retrieval functionality (Dinelli et al., 2004).

With the Geo-fit MIPAS observations taken along the orbit track are analyzed in two dimensions by exploiting the fact that the limb sequences are continuously repeated along the plane of the orbit. To account for deviations of the pointing from the orbit plane (see Sect. 1.1), a zonally homogeneous atmosphere is assumed (see details and impact of this assumption in Dinelli et al., 2010). This repetition makes it possible to gather the information about a given location of the atmosphere from all the lines of sight that cross that location whatever sequence they belong to. Since the loop of overlap between nearby sequences closes when the air mass measured by the starting sequence is observed again at the end of the orbit, in a retrieval analysis the full gathering of information can be obtained by merging in a simultaneous fit the observations of a complete orbit. The Geo-fit approach operates a 2-D discretization of the atmosphere which enables to model horizontal atmospheric inhomogeneities.
One feature of Geo-fit is that the retrieval grid is independent of the measurement grid so that atmospheric profiles can be retrieved with horizontal separations different from those of the measured limb scans. This feature makes it possible to define the horizontal resolution of the retrieval on the basis of its trade-off with the precision of the retrieval parameters (Carlotti et al., 2007).

The MTR approach enables to perform the simultaneous retrieval of different targets in order to minimize the systematic error components due to the spectroscopic intereference of diverse species. In GMTR, the simultaneous retrieval is performed on $p, T, \mathrm{H}_{2} \mathrm{O}$ and $\mathrm{O}_{3}$, then followed by the individual retrieval of all other targets. The better quality of the MTR products reduces the systematic errors propagated on subsequent targets.

The data of GMTR will be designated MIPAS2-D in what follows.

\section{Survey of the anomaly}

To explore the problem broached in Sect. 1.2 we examined retrieval results of a time span from the beginning of the 

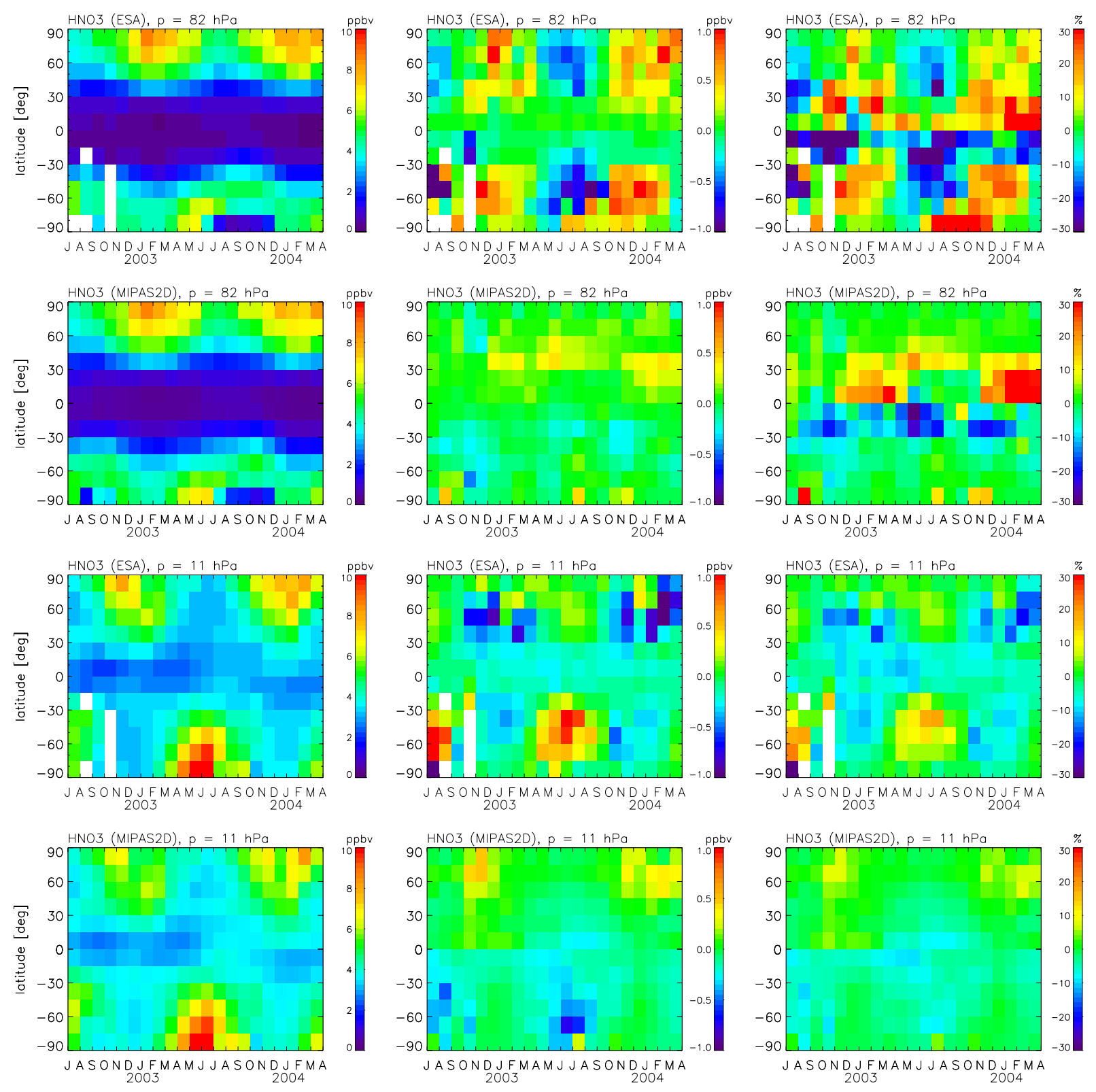

Fig. 6. Distribution of average $\mathrm{HNO}_{3}$ (left column), ascending/descending differences (middle), and relative differences (right) for ESA 1-D and MIPAS2-D data at $82 \mathrm{hPa}$ (first and second row, respectively), and at $11 \mathrm{hPa}$ (third and last). Data bins are the same as in Fig. 4.

mission in mid 2002 to the temporary break in March 2004 of several 1-D L2 processors (ESA, Oxford, and IMK/IAA) and 2-D results (Bologna) for several species.

\subsection{Analysis method}

For each of the 1-D processors and for the 2-D processor the data was treated in the following manner: first, all vertical profiles of volume mixing ratios were interpolated onto a fixed reference pressure grid, which is equivalent to a $1 \mathrm{~km}$ altitude grid. Then the whole data set was separated into data of geolocations of ascending and of descending orbit parts. In the next step each of these ascending/descending subsets was sorted into time bins of 30.4369 days (representing the length of a mean month) and latitude bins of $15^{\circ}$. Special care was taken to guarantee that the averaged latitudes of contributing geolocations within corresponding ascending/descending latitude bins do not differ more than $0.2^{\circ}$ to avoid unwanted biasing of either subset. Finally, mean profiles within the time/latitude bins were calculated. Hence for each bin there are two mean profiles: one calculated from profiles of the ascending and one calculated from profiles of the descending part of the orbit. 

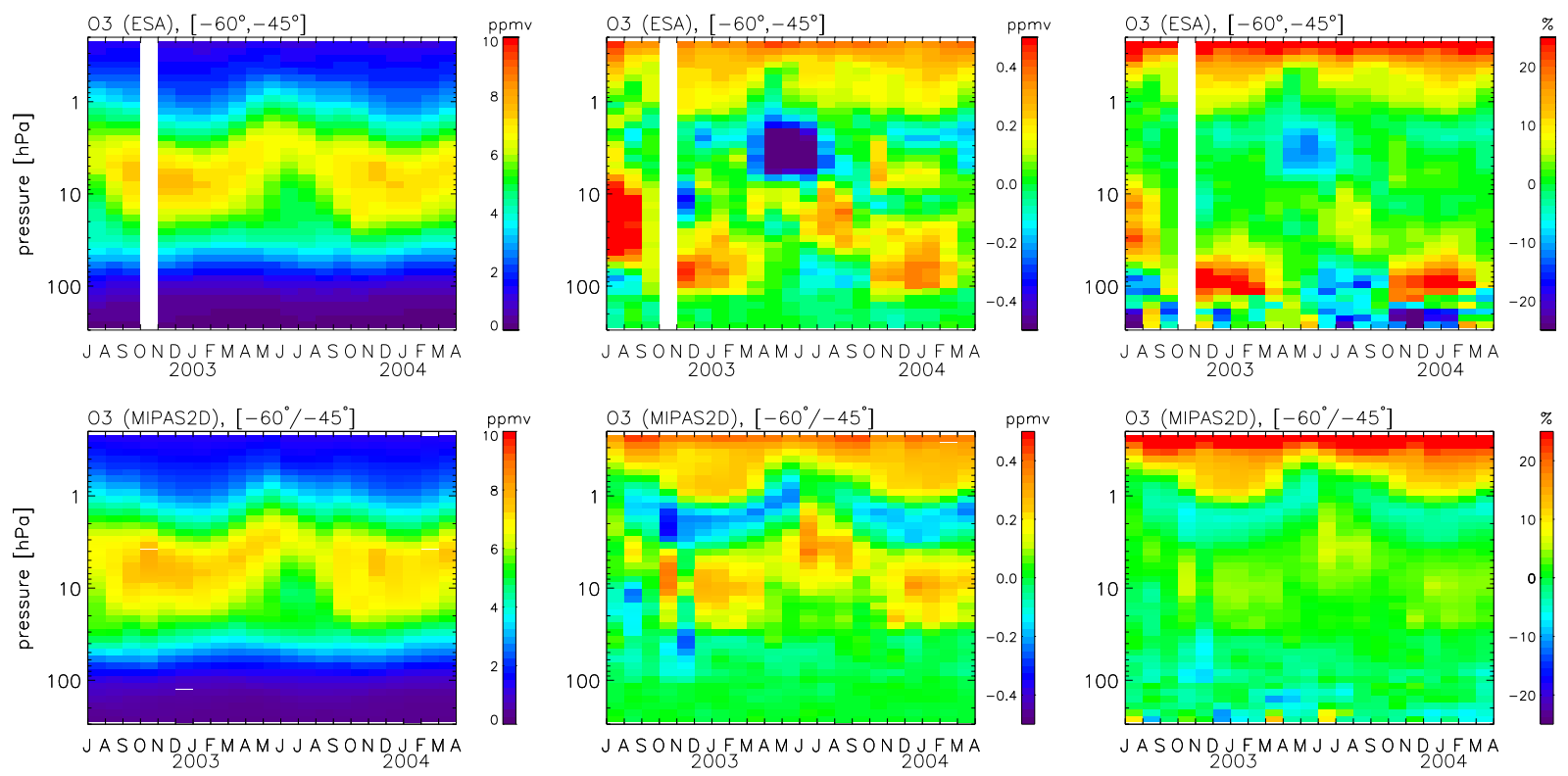

Fig. 7. Same as Fig. 3, but for $\mathrm{O}_{3}$ of ESA 1-D (top) and MIPAS2-D (bottom) retrievals.

In the following we present mean profiles, which are calculated as mean of ascending and descending profiles, difference profiles, which represent the differences of the means between ascending and descending data (i.e. ascending minus descending), and relative differences, which are the latter divided by the former. Atmospheric pressure is used as the vertical coordinate throughout the study.

We concentrate mostly on the latitude band from $65^{\circ} \mathrm{S}$ to $45^{\circ} \mathrm{S}$ where the anomaly can be seen very clearly. However, there is an electronic supplement to this paper, which contains plots for all latitude bands. We shall use negative/positive signs of latitudes synonymous to $\mathrm{S} / \mathrm{N}$ indicators for southern/northern latitudes.

The data coverage strongly depends on the year and month and a little bit on the altitude. Between 10 and 500 single profiles are used for the monthly means and differences calculations for each latitude band. After December of 2002 for each month there are more than 150 profiles per month available to calculate means and differences. Half of those months got more than 250 geolocations. However, at altitude levels below $200 \mathrm{hPa}$ the numbers are considerably reduced since cloud contaminated altitudes were rejected.

\subsection{Results for temperature and key species}

We present here the analysis of ascending/descending differences for temperature and a number of key species retrieved from MIPAS spectra, which all have a fundamental role for the greenhouse effect and/or ozone chemistry. Temperature is a key quantity in the analysis of mid/thermal IR spectra since the strength of the spectral emission lines directly depends on the temperature. The analyzed gases have different spatial distributions and they cover the typically observed scenarios of atmospheric gradients. In particular, CFC-11 originally discussed by Höpfner et al. (2007) is taken as an example of a gas of tropospheric origin, $\mathrm{HNO}_{3}$ for gases with strong local production in the stratosphere. Water vapour is discussed separately for its peculiar distribution. $\mathrm{CH}_{4}, \mathrm{~N}_{2} \mathrm{O}$ and $\mathrm{CFC}-12$ are briefly reported to show the level of consistency among the gases.

As already noted in Sect. 1.1 ascending and descending parts of the orbit largely correspond to day and night conditions. A diurnal variation of temperature or of species' volume mixing ratios will consequently have an effect on the ascending/descending differences presented here. So first we look into the expected diurnal variations in the altitude range considered here: to assess the expected temperature variations we will use ECMWF reanalysis data in the section on ascending/descending differences in temperature directly. CFC-11, CFC-12, $\mathrm{CH}_{4}$, and $\mathrm{N}_{2} \mathrm{O}$ do not have sources in the lower and middle stratosphere, so no diurnal variation is expected. Ozone does show a diurnal variation at altitudes of approximately $50 \mathrm{~km}$ and above, while $\mathrm{HNO}_{3}$ is expected to show a significant variation already at $40 \mathrm{~km}$, but none in the lower stratosphere at $20 \mathrm{~km}$ (Brasseur and Solomon, 2005). For water the photochemical lifetime is of the order of several months in the altitude range considered (Brasseur and Solomon, 2005), so no diurnal variation is expected.

In the following, temperature and species are discussed adopting specific 1-D retrieval algorithms which most clearly depict the anomalous behaviour or have the best time coverage. Unless specific comments are made, results from the different 1-D retrievals are consistent in terms of the main altitude/latitude/time features of the anomaly. 

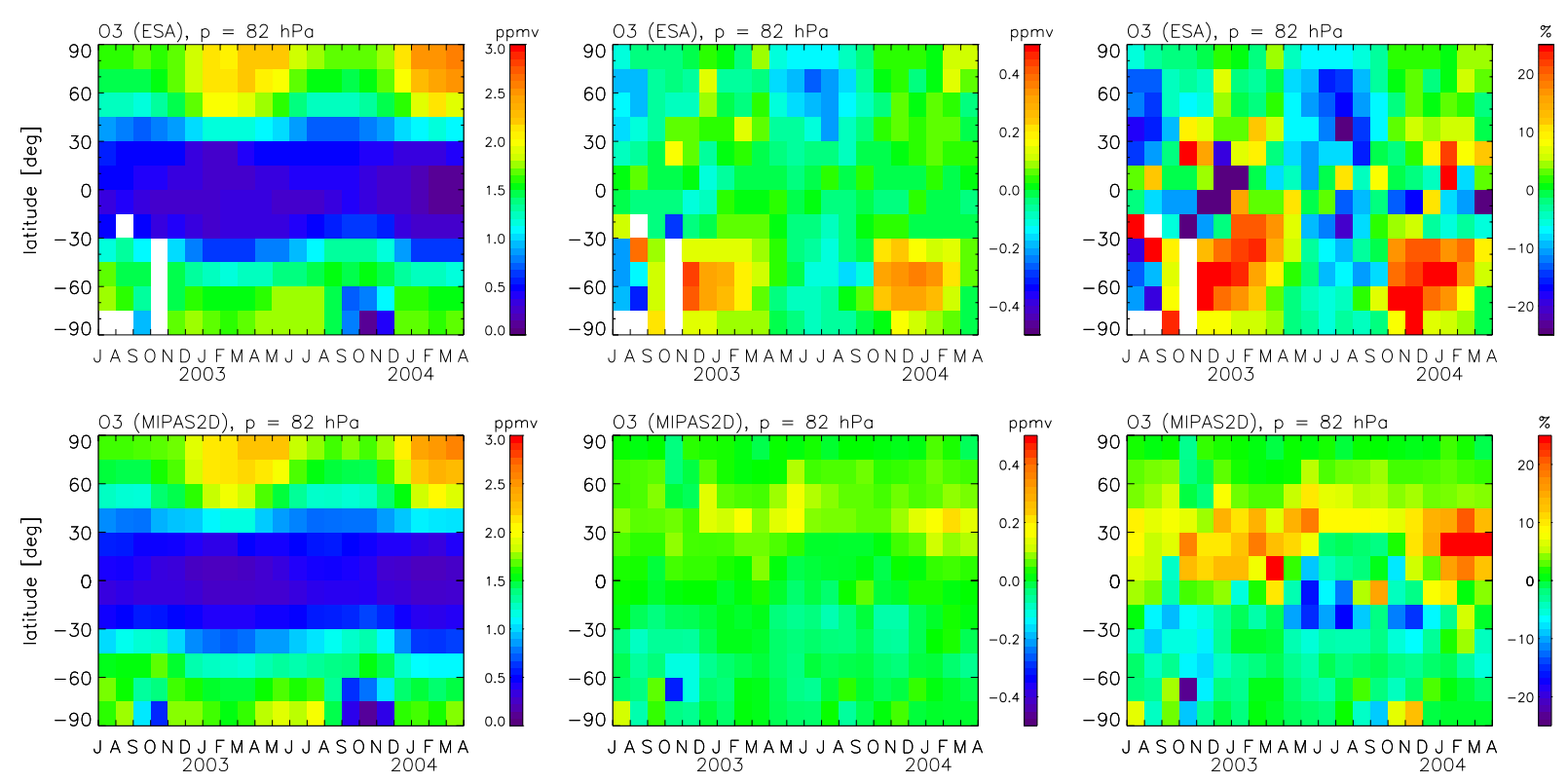

Fig. 8. Distribution of average $\mathrm{O}_{3}$ (left column), ascending/descending differences (middle), and relative differences (right) for ESA 1-D data at $82 \mathrm{hPa}$ (first row) and MIPAS2-D (second row). Data bins are the same as in Fig. 4.

\subsubsection{Temperature}

Figure 1 shows pressure versus time plots of monthly mean temperatures, ascending minus descending differences of temperature, and relative differences for the latitude bin $60^{\circ} \mathrm{S}-45^{\circ} \mathrm{S}$. For the top row plots the temperature data was taken from ECMWF reanalyses. This data is taken as reference, especially for the difference data, because in temperature a day/night difference is expected. The second, third, and fourth row show data of the IMK/IAA, Oxford, and ESA 1-D processors, respectively, while in the last row MIPAS2$\mathrm{D}$ data is shown.

Generally, the mean temperatures (first column) of ECMWF, 1-D and 2-D processors coincide quite well in pattern and magnitude. However, in the ascending/descending differences (second column) there are considerable disagreements. The ECMWF reference data features a weak annual cycle of amplitude $1 \mathrm{~K}$. All data of 1-D retrievals show a clear annual cycle between $5 \mathrm{hPa}$ and $200 \mathrm{hPa}$ with amplitudes of up to $5 \mathrm{~K}$. Between these altitude levels MIPAS2-D data exhibits only a weak cycle with amplitudes of approximately $1 \mathrm{~K}$. A common feature of all difference patterns is a phase shift of the annual cycle with pressure level: Max$\mathrm{ima} /$ minima are reached $2-3$ months earlier at $10 \mathrm{hPa}$ than at $100 \mathrm{hPa}$ level.

\subsubsection{CFC-11}

The first trace gas we analyze is CFC-11. Once released in the troposphere, the long lived gas is characterised by a height independent vmr in the troposphere, and strato- spheric gradients which are generally negative with latitude and altitude.

Figure 3 contains pressure versus time plots for the latitude bin $60^{\circ} \mathrm{S}-45^{\circ} \mathrm{S}$. The ascending/descending differences in 1-D data (first two rows, second and third column from the left) show a pronounced annual cycle with higher CFC-11 in profiles of ascending orbit parts during northern summer and lower values during northern winter with a similar time behaviour among the 1-D processors. Peak values are reached at $70-100 \mathrm{hPa}$ for IMK/IAA and $100-200 \mathrm{hPa}$ for Oxford data. In general the most pronounced differences for Oxford data are located mostly in the region where the CFC-11 profile still is almost constant or has a weak vertical gradient, while the IMK/IAA's CFC-11 differences are mostly found in the region of the greatest vertical CFC-11 gradient. This might be caused by the different methods of constraining the retrieval, see Sects. 2.2.2 and 2.2.3. Both datasets show maximum relative differences of more than $\pm 20 \%$ below $70 \mathrm{hPa}$ (the pressure level at which CFC-11 has decreased to approximately half of the ground/maximum value). Large relative differences above $20-30 \mathrm{hPa}$ are due to low absolute values of CFC-11 at these altitudes.

MIPAS2-D data do not show a clear pattern below $40 \mathrm{hPa}$ neither in terms of absolute or relative differences. The ascending/descending differences rather are close to zero or do exhibit a seemingly random pattern above $80 \mathrm{hPa}$. Only relative differences at pressure levels around $30 \mathrm{hPa}$ depict an annual cycle with amplitude comparable to that of the 1-D data, while the phase is shifted by $1 / 2$ year at a magnitude comparable to measurement uncertainties. 

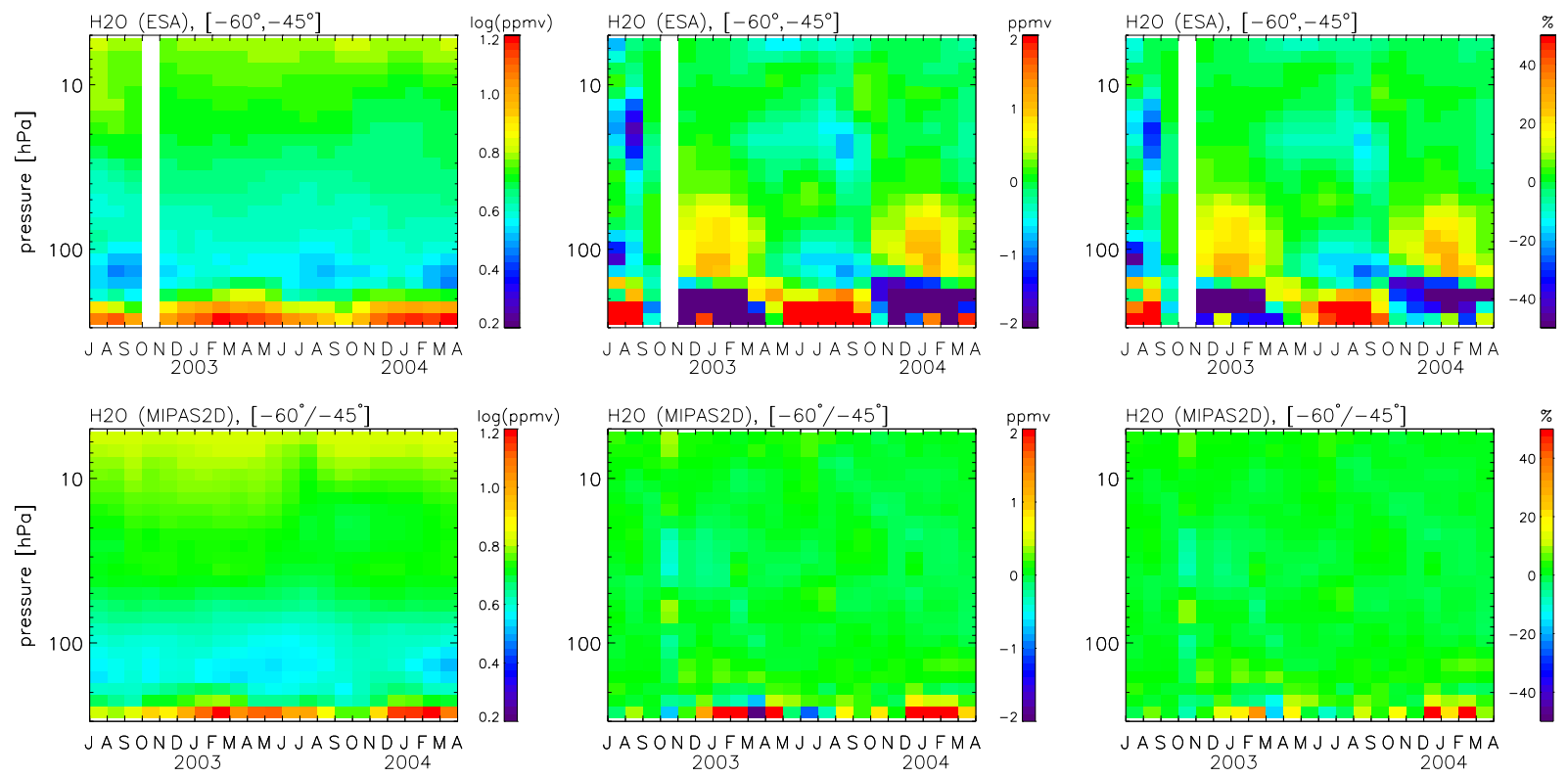

Fig. 9. As Fig. 3, but for ESA (top) and Bologna MIPAS2-D (bottom) L2 data of $\mathrm{H}_{2} \mathrm{O}$. Note that the plot of the average data has a logarithmic scaling of the values, while absolute and relative differences have a linear one and that the scale of the relative errors is larger ( $\pm 50 \%)$ than with the other species shown.

In Fig. 4 Oxford and MIPAS2-D data are displayed in latitude versus time plots at $82 \mathrm{hPa}$. In both hemispheres, the sign of the differences in 1-D data is essentially the same for all latitudes for a given time. However, the sign changes in the course of the year, but not with local season. Ascending data exhibits greater vmr values than descending data around JJA-months and smaller values around DJF-months. At this pressure level the major differences are located in the Southern Hemisphere in a band from $30^{\circ} \mathrm{S}-90^{\circ} \mathrm{S}$. In the Northern Hemisphere the amplitude of the annual variation of the differences is weaker than in the south. CFC-11 of IMK/IAA (not shown in the Figure) exhibits a very similar pattern, albeit again somewhat weaker than that found in Oxford retrievals.

There are no indications for an annual cycle in MIPAS2-D data, values of the ascending/descending differences, either absolute or relative, are much lower than in 1-D data.

\subsection{3 $\mathrm{HNO}_{3}$}

Figure 5 shows the same type of plots as in Fig. 3 for IMK, ESA and MIPAS2-D $\mathrm{HNO}_{3}$ data. Again an annual cycle can be seen in 1-D data, albeit the vertical structure of the difference profiles is distinct from that of CFC-11: ascending/descending differences change sign with altitude. The greatest absolute and relative differences are located at altitude regions where $\mathrm{HNO}_{3}$ is rapidly varying with altitude. The sign of the differences at altitudes where the vmr decreases with height is consistent with the behavior of CFC-11 (mean values constant or decreasing with altitude). Relative differences of up to $20 \%$ may occur where $\mathrm{HNO}_{3}$ values are still greater than half of the profile peak value.

Below $10 \mathrm{hPa}$ there are virtually no relative differences in MIPAS2-D data.

In Fig. 6 latitude versus time plots at $82 \mathrm{hPa}$ and at $11 \mathrm{hPa}$ (i.e. at pressure levels where $\mathrm{HNO}_{3}$ is increasing and decreasing with altitude, respectively) are shown for ESA $\mathrm{HNO}_{3}$ data and for MIPAS2-D data. For middle and high latitudes 1-D data at $82 \mathrm{hPa}$ features a similar pattern, albeit with opposite sign, compared to CFC-11 in the absolute differences. The sharp jump of the sign of the relative differences is due to extremely low $\mathrm{HNO}_{3}$ volume mixing ratios around the equator. The time/latitude pattern of differences at a higher altitude $(11 \mathrm{hPa})$ shows the same sign of the differences as the corresponding CFC-11 plot (Fig. 4). So again in both hemispheres, the sign of the differences in 1-D data essentially is the same for a given time and altitude.

MIPAS2-D absolute differences at the $82 \mathrm{hPa}$ level show some distinct features, but again there is virtually no coincidence with those of 1-D data. At $11 \mathrm{hPa}$ the picture is different: the annual cycle is weaker with a phase shift of 6 months.

\subsubsection{Ozone}

ESA and MIPAS2-D data of $\mathrm{O}_{3}$ are depicted in Fig. 7. Due to photolysis, ozone concentrations are subject to day/night changes at altitudes of $45 \mathrm{~km}$ and higher up. Therefore only data from altitudes significantly below $45 \mathrm{~km}$ (roughly $1 \mathrm{hPa}$ ) will be considered in the discussion of the differences. At 

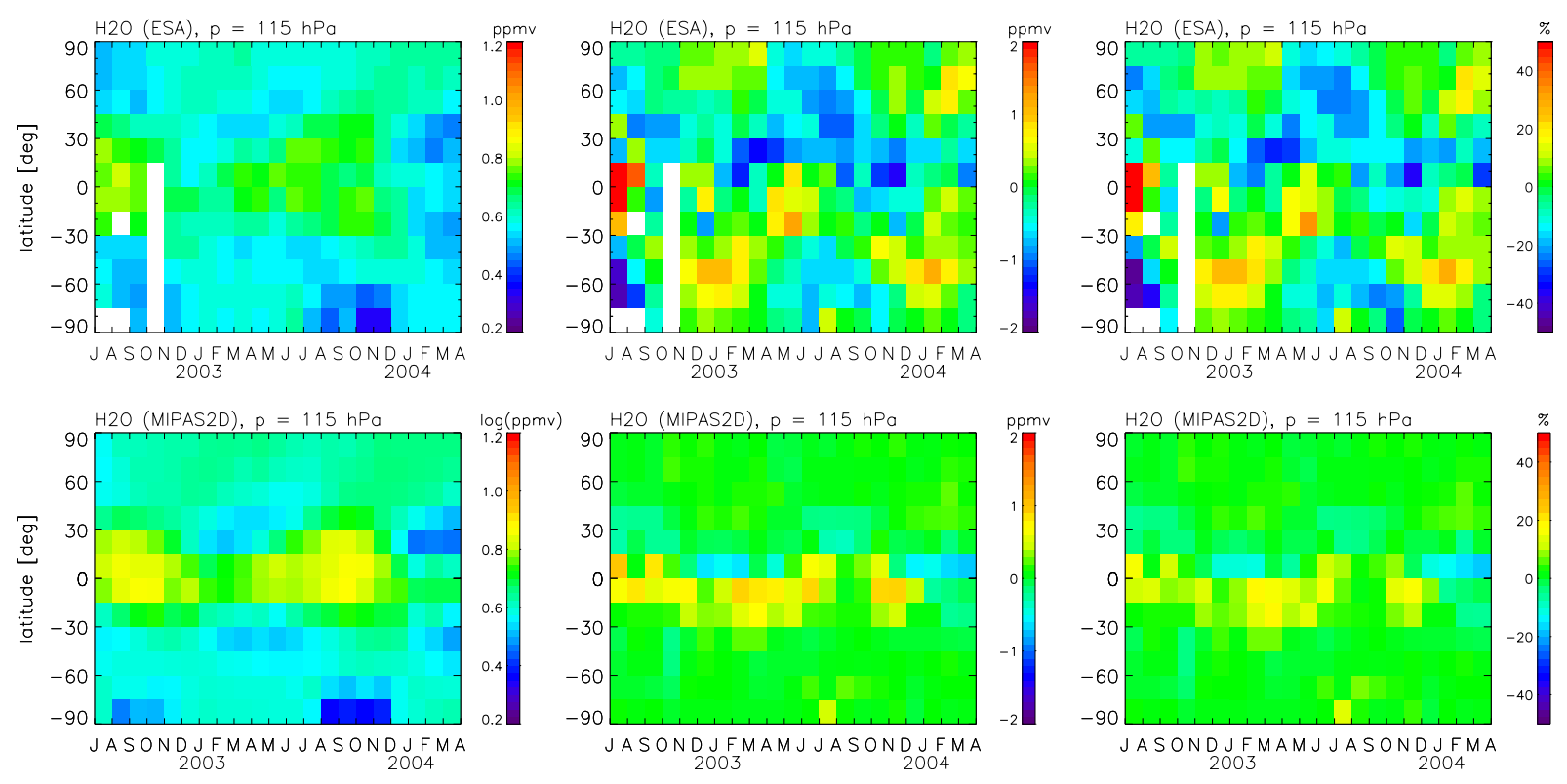

Fig. 10. As Fig. 4, but water vapour for ESA data at $115 \mathrm{hPa}$ (top row) and MIPAS2-D data at $115 \mathrm{hPa}$ (bottom).

$50-100 \mathrm{hPa}$ there is a clear annual cycle with the phase corresponding to that of $\mathrm{HNO}_{3}$ in the same pressure level range. This again is an indication that the vertical gradient of the profile gives the sign of the phase of the annual cycle, since both species show an increase with altitude there. However, in the altitude range of decreasing Ozone there is no annual cycle of opposite phase, but rather a marked feature at 2$6 \mathrm{hPa}$ in MAMJJ months of 2003 which does not fit well into the DJF/JJA pattern seen in the species dicussed so far. Maximum relative differences of up to $25 \%$ occur at $50-100 \mathrm{hPa}$, however, at altitudes with more than 4 ppmv (half of the Ozone peak value) only differences of up to $10 \%$ emerge. It has to be noted that ESA and Oxford (not shown) data coincide very well, while IMK (not shown) data does show a much different behaviour above $20 \mathrm{hPa}$.

In MIPAS2-D data absolute differences show maxima where Ozone is high, but there is no change of the sign around this pressure level of 5-10 hPa. The same features are visible in relative differences with maximum values of $5 \%$. Altogether the pattern does not have a strong coincidence with that of 1-D data, but ascending/descending differences can clearly be seen.

From Fig. 8 it can be seen that again 1-D differences have the same sign for northern and southern hemispheres for a given time, yet the amplitude is significantly stronger at southern latitudes.

MIPAS2-D data shows a pattern similar to the one of MIPAS2-D $\mathrm{HNO}_{3}$ at $82 \mathrm{hPa}$. Again there seems to be no stringent correlation to the pattern of 1-D data.

\subsection{5 $\quad \mathrm{H}_{2} \mathrm{O}$}

Figure 9 gives a view on the behaviour of ESA and MIPAS2$\mathrm{D}$ water vapour. At and below $200 \mathrm{hPa}$ there is a clear annual cycle in 1-D data with the phase as in CFC-11, with the extremal relative differences reaching more than $50 \%$. A cycle with reversed phase and maximum amplitude of $20 \%$ is discernible at altitudes around $115 \mathrm{hPa}$. The pressure level of approximately $160 \mathrm{hPa}$ which divides the two phase regimes is close to the level of minimum water vapour vmr (left plot). Altitude regions of very large vertical negative gradients, essentially those below the tropopause, exhibit very high differences compared to the other species discussed so far. Again, the sign of the differences directly depends on the sign of the vertical vmr gradient. The cross section at pressure level $115 \mathrm{hPa}$ (Fig. 10) shows in 1-D data a pattern which correlates partly with that of $\mathrm{HNO}_{3}$ at $82 \mathrm{hPa}$, but is not very clear.

No annual cycle can be seen in 2-D data. However, ascending/descending differences are found at low latitudes.

\subsubsection{CFC-12, $\mathrm{CH}_{4}, \mathrm{~N}_{2} \mathrm{O}$}

Beyond the species presented already, several more were processed by the diverse MIPAS L2 processors and a selection of these was analyzed with the same method. In Fig. 11 the features of mean vmr values and relative differences of CFC-12, $\mathrm{CH}_{4}, \mathrm{~N}_{2} \mathrm{O}$ of Oxford 1-D and Bologna MIPAS2-D in the latitude bin $60^{\circ} \mathrm{S}-45^{\circ} \mathrm{S}$ are shown. 

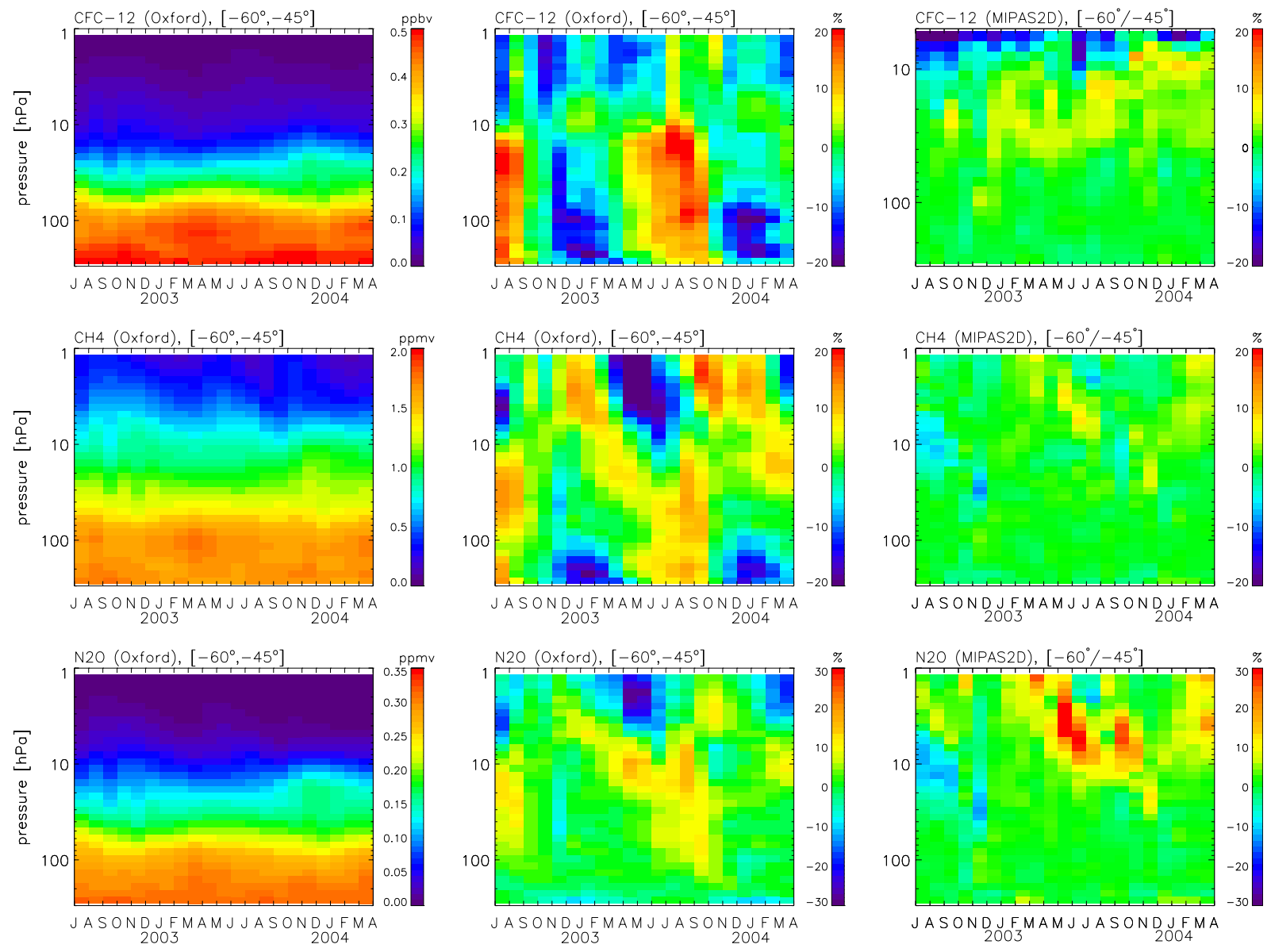

Fig. 11. Absolute values of Oxford (left column) and relative differences of Oxford (middle column) and Bologna MIPAS2-D (right column) of $\mathrm{CFC}-12, \mathrm{CH}_{4}$, and $\mathrm{N}_{2} \mathrm{O}$ (top to bottom row, respectively) in the latitude bin $60^{\circ} \mathrm{S}-45^{\circ} \mathrm{S}$.

\section{CFC-12}

As already noted by Höpfner et al. (2007) there is also an effect in an old data version of IMK/IAA CFC-12 (Fig. 11 shows Oxford data due to better coverage). The overall picture is much like in CFC-11 of Oxford. Differences are pronounced in the altitude region below $10 \mathrm{hPa}$. Again the maximum relative differences reach $\pm 20 \%$ below the level of approximately half of the ground vmr value (at $40 \mathrm{hPa}$ ), while MIPAS2-D data does not show any clear pattern.

\section{$\mathrm{CH}_{4}$}

Up to approximately $30 \mathrm{hPa}$ there is a clear annual cycle with the relative difference amplitude reaching $15 \%$. The phase of this cycle is consistent with that of CFC-11 up to $10 \mathrm{hPa}$. Above $10 \mathrm{hPa}$, at altitude levels where $\mathrm{CH}_{4} \mathrm{vmr}$ is still a quarter of the ground value, there is a reversal of the sign of the annual cycle. Again there are no noticeable features in MIPAS2-D data.
$\mathbf{N}_{2} \mathbf{O}$

A weak annual cycle, roughly consistent with CFC-11 is visible up to approximately $10 \mathrm{hPa}$. Maximum differences of $10-15 \%$ occur, but only for positive differences. MIPAS2$\mathrm{D}$ relative differences depict no clear pattern below $10 \mathrm{hPa}$, while above the values are not reliable due to low volume mixing ratios and uncertainties comparable to the observed features.

\section{Discussion}

\subsection{Cause of the anomaly: a hypothesis}

To sum up the findings of the preceding sections: in ascending/descending differences $t$ The majority of the analyzed 1D retrieved data, either temperatur or species, show a distinct annual cycle of ascending/descending differences in the latitude range $60^{\circ} \mathrm{S}-45^{\circ} \mathrm{S}$ at pressure levels of $10-100 \mathrm{hPa}$, which roughly corresponds to $15-30 \mathrm{~km}$ altitude, i.e. to the lower stratosphere. Often an annual cycle is discernible in 

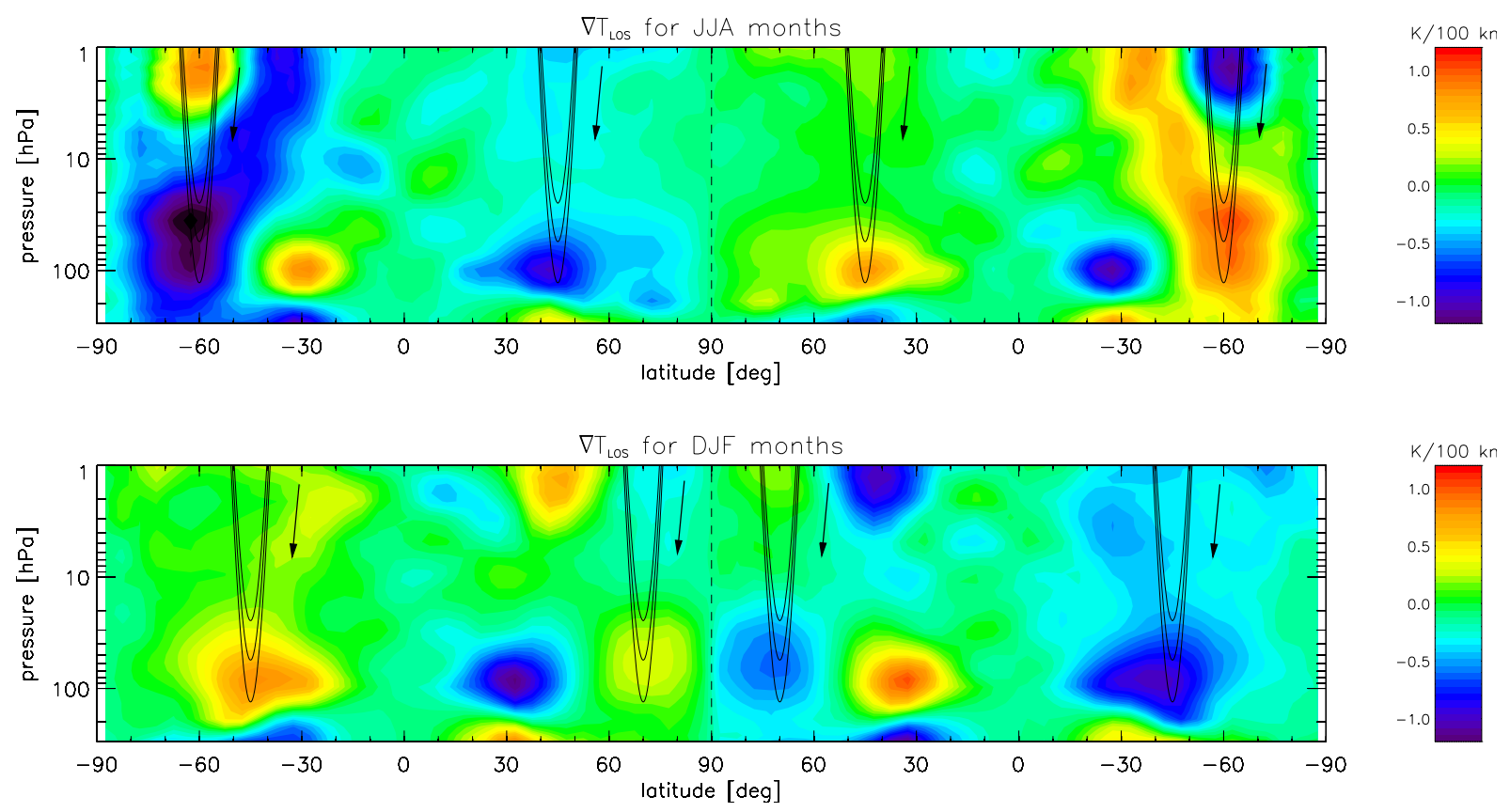

Fig. 12. Horizontal temperature gradient along MIPAS' line of sight at the tangent point averaged for JJA (top) and DJF months (arrows indicate the viewing direction). The gradient is calculated from ECMWF reanalysis temperature fields. The latitude coordinate begins at the South Pole on the left side, first follows the ascending part of an orbit up to the North Pole (broken vertical line at $90^{\circ}$ ), and then follows the descending orbit part down to the South Pole again. Superimposed curves represent MIPAS' line of sight for tangent altitudes 15, 20, and $25 \mathrm{~km}$ for measurement locations at $60^{\circ} \mathrm{S}$ and $45^{\circ} \mathrm{N}$ (top panel) and $45^{\circ} \mathrm{S}$ and $70^{\circ} \mathrm{N}$ (bottom).

other latitudes too, with the sign of the differences at a given time of the year corresponding to that of the differences in $60^{\circ} \mathrm{S}-45^{\circ} \mathrm{S}$ during that time (see also the electronic supplement to this work). Mostly no systematic features are visible in 2-D retrieval data. It has to be noted that diurnal variations would show up as differences with unchanged sign over the time, as e.g. in ozone above $45 \mathrm{~km}$, and that this kind of difference is well visible in 1-D and 2-D retrievals (see Fig. 7, levels above $1 \mathrm{hPa}$ ).

A key point in our analyses is that we only consider differences of mean profiles of ascending and descending orbit parts for each L2 processor, and therefore can assume that most of the differences between the different processors will cancel out to first order. This of course does not hold for systematic errors which depend on the platform's direction of movement or on day and night condidtions (which are largely synonymous to descending and ascending movement), as e.g. influence of non local thermodynamic equilibrium. However, with respect to the case of non local thermodynamic equilibrium special care was taken in the selection of the spectral lines employed in the retrievals, so only very small effects might be expected. Obviously there is an influence of the different regularisation strategies on the differences, as noted in Sect. 3.2.2. However, the main features found in the data are not affected.

The relative lack of systematic features in the 2-D retrieval contrary to the 1-D retrievals suggests that inhomogeneities of the atmosphere might play a role, because a major difference between 1-D and 2-D retrievals is the treatment of atmospheric inhomogeneities. Furthermore, the facts that in the 1-D temperature retrievals there is already a clear effect (see Sect. 3.2.1), and that species retrievals from mid-IR emission spectra strongly depend on temperature, suggest to refine this hypothesis: the major part of the ascending/descending differences of 1-D retrieval results is caused by the neglect of the horizontal temperature inhomogeneities in the retrieval algorithm.

This hypothesis is supported by the findings of several retrieval studies: Stiller et al. (2002) examine the sensitivity of species retrievals to simplifying approximations in radiative transfer modelling for MIPAS spectra. The horizontal structure of the atmosphere is chosen to be consistent with a late winter arctic polar vortex boundary situation. It is found that the most relevant modelling error is the neglect of horizontal gradients in the temperature fields. The associated errors in the model spectra occur close to the line centers in all spectral regions considered. In that study there is also found an effect of horizontal gradients of trace gas abundances. However, only for $\mathrm{HNO}_{3}$ and $\mathrm{ClONO}_{2}$ there is a clear error contribution. For other species, the contribution to the model spectra errors is small (see Table 1 of Stiller et al., 2002).

Carlotti et al. (2001) consider 1-D and 2-D retrievals based on synthetic spectra generated from a realistic atmosphere. They find that the contribution of temperature/pressure 

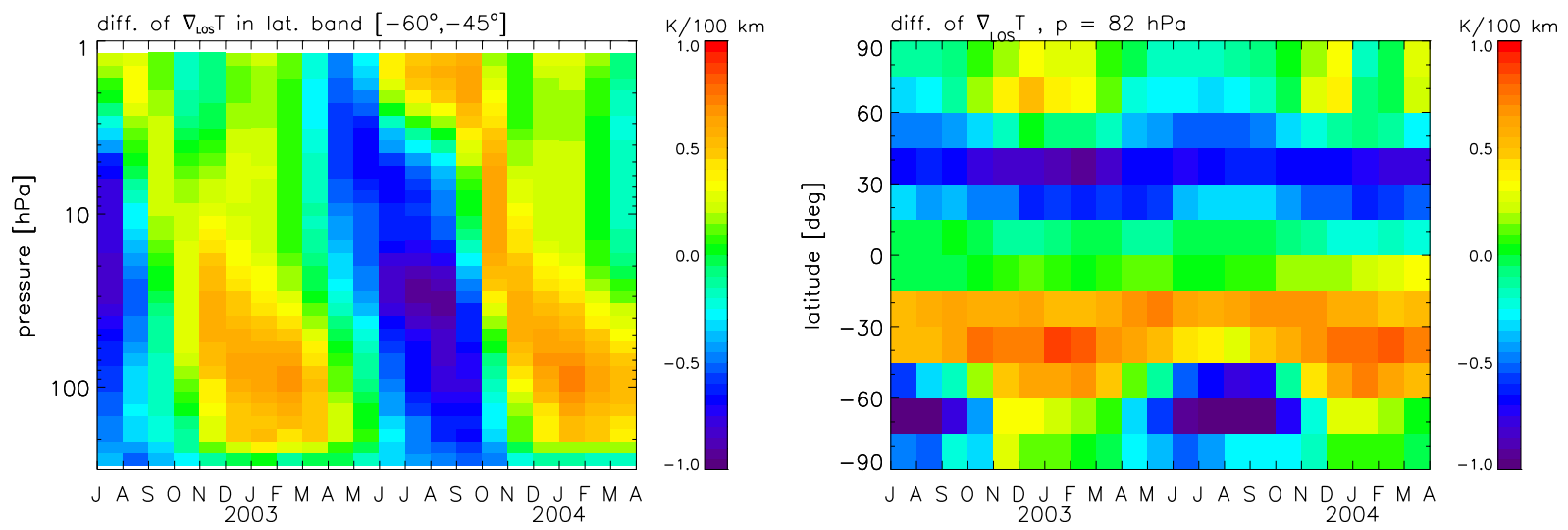

Fig. 13. Differences between ascending and descending orbit parts of horizontal temperature gradients along MIPAS' line of sight at the tangent point. Temperature data was taken from ECMWF reanalysis data on MIPAS measurement geolocations, and the method presented in Sect. 3.1 was applied. Note that additionally a factor of $1 / 2$ has been applied (see text).

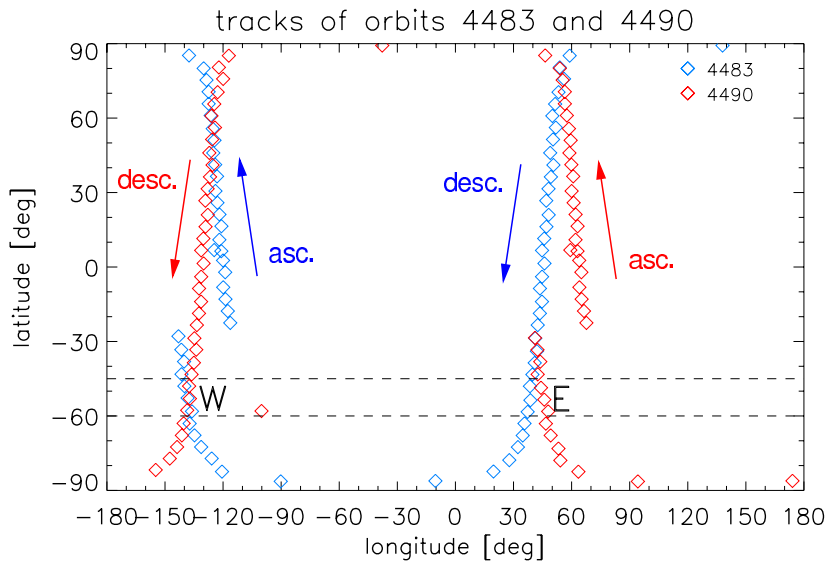

Fig. 14. Geolocations of orbits 4483 (blue) and 4490 (red) selected to illustrate the influence of the inclusion of an external temperature gradient in the forward model of the 1-D retrieval. Ascending parts of the orbits feature an inclination to the left while descending orbit parts are inclined to the right, as indicated by the arrows.

inhomogeneities on the error of the 1-D ozone retrieval, averaged over one orbit, is approximately $50 \%$.

Steck et al. (2005) present 1-D and 2-D retrieval case studies for synthetic MIPAS measurements. A realistic 2-D temperature field of approximately $60^{\circ}$ width in latitude is defined, and synthetic measurements are generated. Then 1$D$ retrievals are performed, based on these synthetic spectra. A comparison with the initial 2-D field shows temperature differences of up to $10 \mathrm{~K}$ in regions with obvious horizontal inhomogeneities.

\subsection{Corroboration of the hypothesis}

\subsubsection{Geometrical consideration}

To confirm the validity of the hypothesis we take several steps: first we look at the geometrical relation of the horizontal temperature gradient and the line of sight of MIPAS. Figure 12 shows the horizontal temperature gradient as seen along the line of sight at the tangent points associated to the pressure given as ordinate. A positive gradient along the line of sight means that around the tangent point the temperature increases with distance from the instrument.

Since MIPAS is essentially looking backwards with respect to the platform's flight direction, the sign of the temperature gradient along the line of sight depends on whether the platform moves on the ascending or descending part of the orbit. In a region with temperature increasing northwards MIPAS sees a negative gradient during ascending and a positve during descending movement, see e.g. the latitude $60^{\circ} \mathrm{S}$ in the upper panel of the figure. The curves superimposed on the gradient field in Fig. 12 represent MIPAS' line of sight for tangent altitudes 15,20 , and $25 \mathrm{~km}$, the altitude region where temperature and most of the targets discussed in the preceding sections show a distinct annual cycle. The signs of the temperature gradients along the line of sight for latitudes with pronounced relative vmr differences (see e.g. Fig. 4), e.g. at $60^{\circ} \mathrm{S}$ or at $45^{\circ} \mathrm{N}$ for JJA months, or $45^{\circ} \mathrm{S}$ and $70^{\circ} \mathrm{N}$ for DJF months, respectively, show the same signs during ascending and descending orbit parts. The reversal of the gradient at $60^{\circ} \mathrm{S}$ for JJA months might partly explain the reversal of the sign in the annual cycle of $\mathrm{CH}_{4}$ differences.

In Fig. 13 we show the ascending/descending differences of the horizontal temperature gradients as seen along the line of sight at the tangent points. Actually the difference is divided by two, so that the modulus is an approximation to the modulus of the horizontal temperature gradient along 

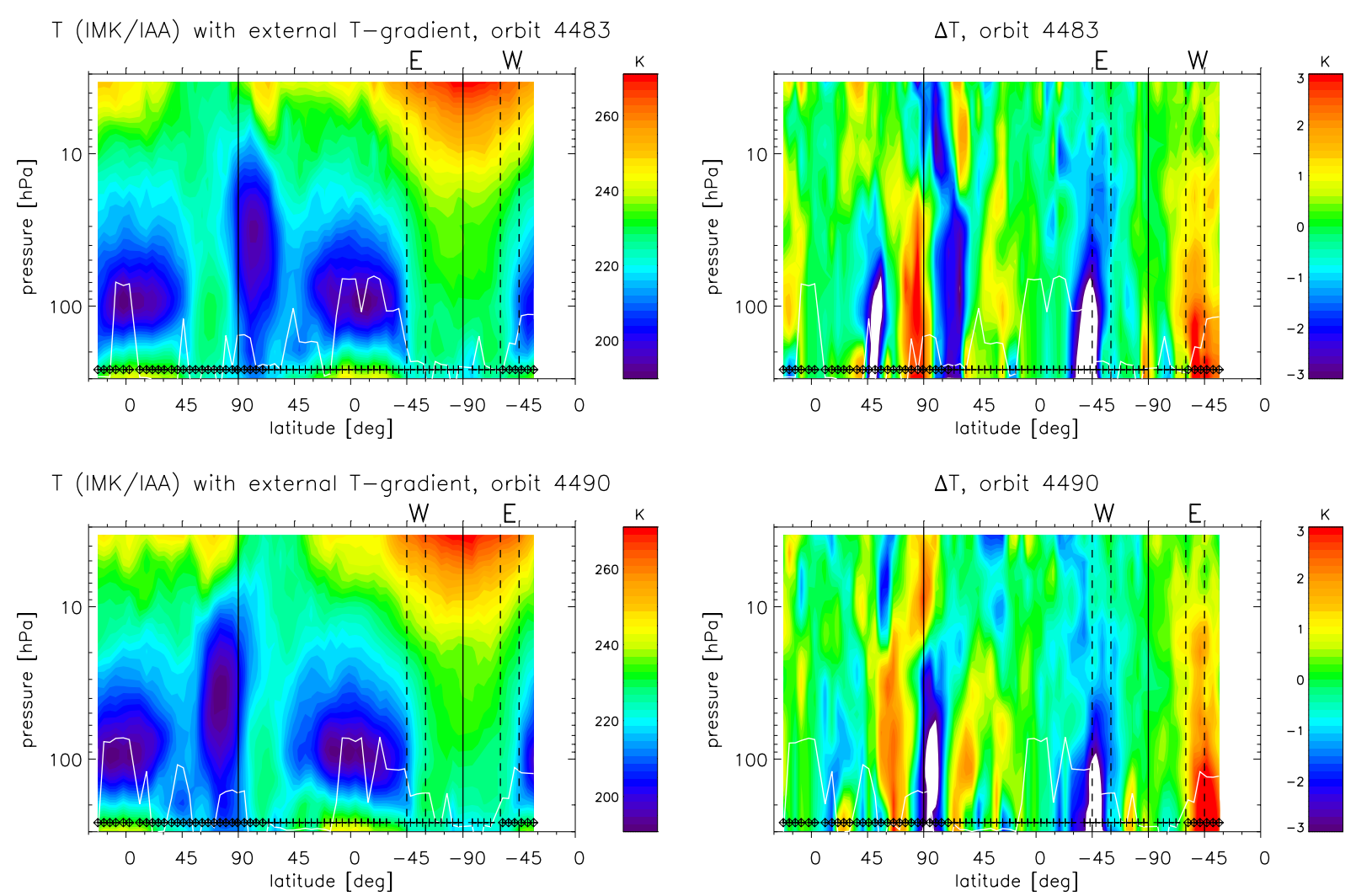

Fig. 15. Temperature field (left column) along orbits 4483 (top row) and 4490 (bottom) as retrieved with the modified IMK/IAA L2 data processor (details see text). The orbit starts at the plot frame's left side at approximately $20^{\circ} \mathrm{S}$. The right column gives the differences in the temperature fields along the respective orbits. Differences are calculated per geolocation as $T$ of modified retrieval minus $T$ of 1-D IMK/IAA data (version V3O_T_8). Vertical lines indicate the latitude band $45^{\circ} \mathrm{S}-60^{\circ} \mathrm{S}$ (dashed) and the poles ( -90 is the South Pole). The continuous line running between the frames' lower boundary and $60 \mathrm{hPa}$ indicates the pressure level of the lowest tangent altitudes used in the retrievals. Near the bottom of the plot frame plus signs indicate measurements with and diamonds measurements without daylight. Capitals $\mathrm{W}$ and $\mathrm{E}$ above the plot frames indicate the longitude regions $115^{\circ} \mathrm{W}$ and $65^{\circ} \mathrm{E}$, respectively (see Fig. 14 and text). Note the interchange of $\mathrm{W}$ and $\mathrm{E}$ between top and bottom row.

latitude. The horizontal gradient along the line of sight in the latitude band $60^{\circ} \mathrm{S}-45^{\circ} \mathrm{S}$ shows a periodic pattern over the course of the year with extremal values around DJF and JJA months and a negative phase shift with altitude. The pattern in this figure's left plot and that of ascending/descending differences of 1-D temperature retrievals (see rows 2-3 of Fig. 1) are almost perfectly anti-correlated. There is also quite a good anti-correlation between the patterns of horizontal cuts as shown in the right plot of Fig. 13 and Fig. 2.

\subsubsection{Consistency check}

The next step to confirm the validity of the hypothesis is to show that the sign of the gradient along the line of sight is consistent with the sign of the ascending/descending differences in temperature. To show this we employ a result of Steck et al. (2005), who find from examination of 2-D derivatives that the peak contribution to the spectrum is shifted away from the tangent point towards the instrument, and of von Clarmann et al. (2009a), who analyze 2-D averaging kernels and confirm this finding and quantify the shift for temperature to be $50-100 \mathrm{~km}$.

Without loss of generality, we take as an example the latitude $60^{\circ} \mathrm{S}$ from the upper plot of Fig. 12 (JJA months) and the $60 \mathrm{hPa}$ altitude level. On the ascending part of the orbit (left half of the plot) there is a negative horizontal temperature gradient along the line of sight, i.e. the temperature increases from the tangent point towards the instrument. Consequently the peak contribution to the spectrum originates from a higher temperature as compared to that at the tangent point. On the descending part the conditions are reversed, the peak contribution to the spectrum originates from a lower temperature. Hence the 1-D retrieval result of temperature will tend to higher values for ascending and to lower values for descending orbit parts. The difference ascending minus descending therefore will be positive. This finding is consistent with Fig. 1, in JJA months there is a positive difference at $60 \mathrm{hPa}$. From this we can state that the good 

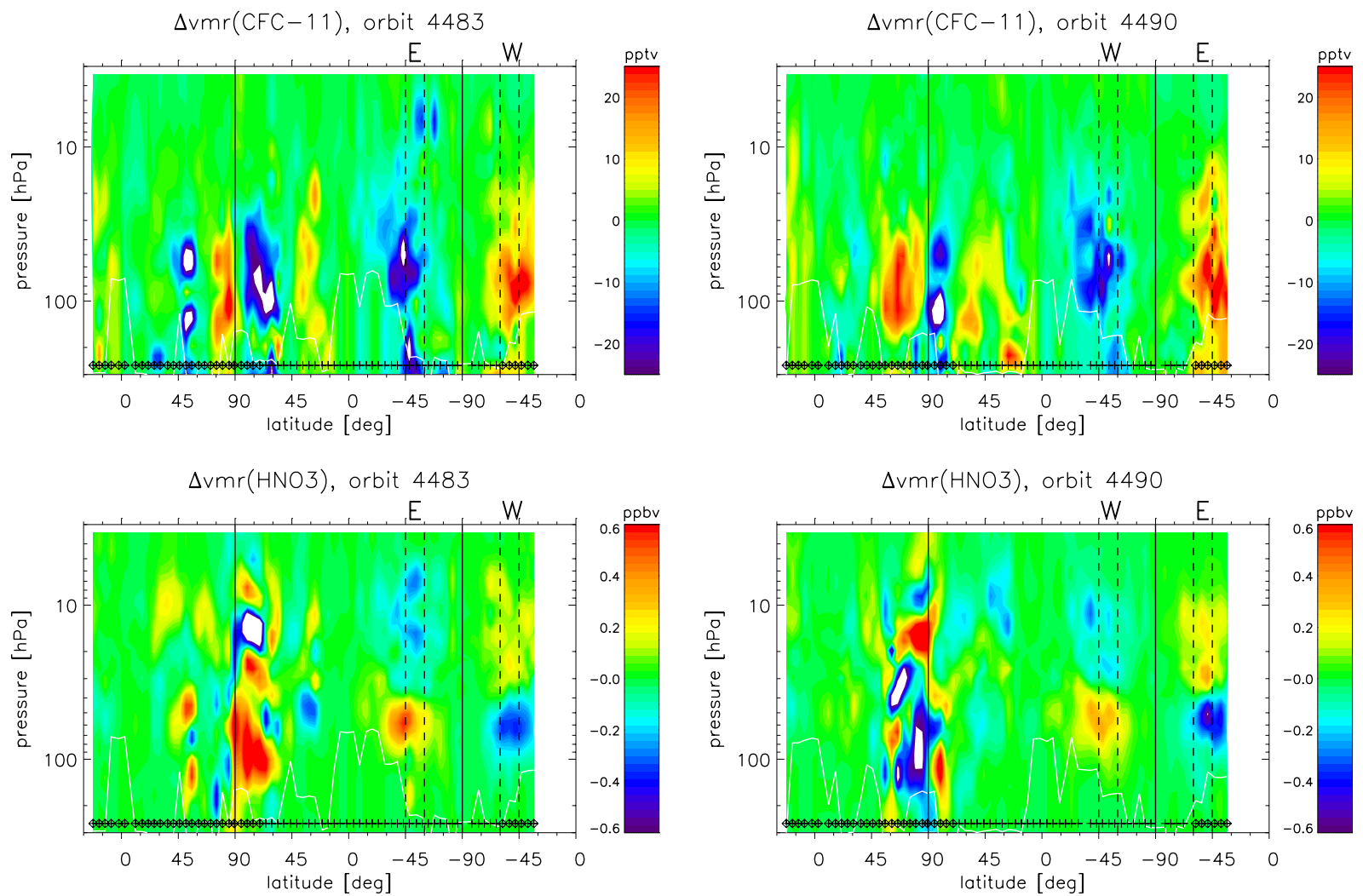

Fig. 16. Absolute differences between retrieval data of modified and original 1-D processing for vmr of $\mathrm{CFC}-11$ (top row) and $\mathrm{HNO}_{3}$ for orbits 4483 (left column) and 4490. Meaning of vertical and other lines and symbols as in Fig. 15. Note the interchange of W and E between top and bottom row.

anti-correlation of the patterns of Figs. 1 and 2 on the one hand, and Fig. 13 on the other, is a strong indication that our hypothesis is sound.

\subsubsection{Modified 1-D retrievals}

Our last confirmation step is to perform a modified 1-D retrieval to quantify the influence of the first order part of the temperature field inhomogeneities, namely the horizontal gradients, on the retrieval. A data set of nine days from the time span 7 to 20 January 2003 was processed with the IMK/IAA L2 processor using a modified setup. This modified setup consists of the inclusion of a prescribed horizontal temperature gradient in the forward modelling of the radiance spectrum during the temperature and line of sight retrieval. The temperature gradient is calculated by finite differences from ECMWF reanalysis temperature data (ERAInterim) at each actual time/location of MIPAS measurements. The horizontal extension of the region influenced by the non-zero temperature gradient was assumed to be $400 \mathrm{~km}$. From experience at IMK for many atmospheric situations this is a reasonable value to take. However, the optimal value depends on the actual state of the atmosphere. E.g., near the polar vortex boundary, $400 \mathrm{~km}$ might be even too large, because the region where the region is applicable is confined to a narrow area. The subsequent species retrievals were then fed with the temperature profile and line of sight information of this modified first step in the retrieval chain and also with the prescribed horizontal temperature gradient. No other changes in the retrieval of the species were made.

The orbit pair 4483 and 4490 of 8 January 2003 is used to illustrate the effects of the changed retrieval setup. The orbits were chosen such that in the latitude range $60^{\circ} \mathrm{S}-45^{\circ} \mathrm{S}$ the geolocations have approximately the same longitude values, as it can be seen in Fig. 14. The key difference in this orbit pair is that MIPAS scans the region during an ascending orbit part for the one and during a descending part for the other one, with a time lag of approximately $12 \mathrm{~h}$. In what follows we shall call the area at $60^{\circ} \mathrm{S}-45^{\circ} \mathrm{S} / 115^{\circ} \mathrm{W}$ region $\mathrm{W}$ and at $60^{\circ} \mathrm{S}-45^{\circ} \mathrm{S} / 65^{\circ} \mathrm{E}$ the region $\mathrm{E}$.

Figure 15 shows the temperature field $T$ along the orbit and differences in the temperature field (i.e. temperature of modified setup minus temperature of data version V3O_T_8) caused by the inclusion of the horizontal temperature gradient. Obviously, differences are large in regions where the horizontal temperature gradient is most pronounced. This is the case for the latitude region $45^{\circ} \mathrm{S}-60^{\circ} \mathrm{S}$ as well as 

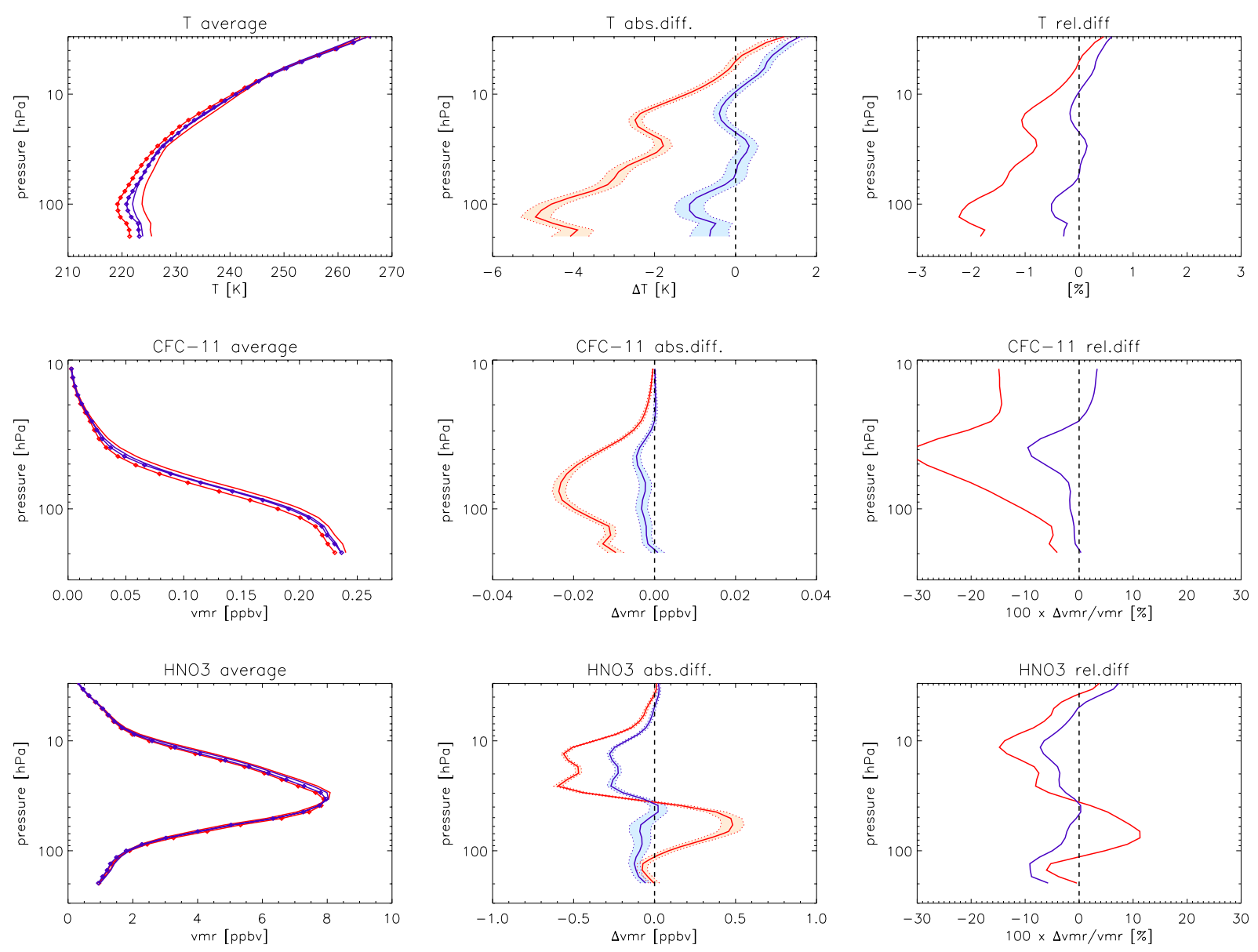

Fig. 17. Compilation in the latitude band $60^{\circ} \mathrm{S}-45^{\circ} \mathrm{S}$ of the differences between data of ascending and descending orbit parts for the old IMK/IAA data (red curves) and for the data from the modified IMK/IAA processor (blue). Averages over nine days are shown in the left column for temperature (top row), CFC-11 (middle), and $\mathrm{HNO}_{3}$ (bottom); data is separately averaged for ascending (solid line) and descending (solid line with symbols) orbit parts. Absolute differences between ascending and descending data are shown in the middle, relative differences are presented in the right column.

in the vicinity of the winter pole (northern polar vortex). Differences of $\pm 3 \mathrm{~K}$ occur below $100 \mathrm{hPa}$. Above $\pm 1-2 \mathrm{~K}$ are found.

It is essential that although the difference plots for the two orbits look quite similar, there is a major difference in that the signs of the differences are opposite for each of the regions $\mathrm{E}$ and $\mathrm{W}$ (notice the reversal of the relative position of $\mathrm{E}$ and $\mathrm{W}$ in the two orbits).

In Fig. 16 the resulting absolute vmr differences of CFC11 and $\mathrm{HNO}_{3}$ are presented. Differences are calculated between vmr of the retrievals fed with the changed temperature and including the prescribed gradients, and vmr of data versions V3O_F-11_8 and V3O_HNO3_7. Again the signs of the differences for each of the regions $\mathrm{E}$ and $\mathrm{W}$ only depend on whether the corresponding measurements were taken during an ascending or descending orbit part. Therefore in a difference of means of profiles of ascending orbit parts (W for orbit 4483, E for 4490) and means of profiles of descend- ing orbit parts (E for 4483,W for 4490) the contributions will not cancel out but approximately double the value of a single difference.

A condensed presentation of the differences between the results of the modified processing and the old data is given in Fig. 17 for nine test days. There is a very good agreement between the differences for the results of the original retrieval setup (red curves in Fig. 17) and the values of Figs. 1 (second row), 3 (top row), and 5 (top row). The impact of the IMK/IAA L2 processor modification on the retrieval results (blue curves) is considerable. In the pressure range $10-300 \mathrm{hPa}$ absolute differences decrease clearly. Ascending/descending differences around the $100 \mathrm{hPa}$ level even change from $-4 \mathrm{~K}$ to $-1 \mathrm{~K}$. Obviously these changes in the temperatures by entering the retrieval of CFC-11 have a significant positive impact on the CFC-11 absolute differences. For the V3O_F-11_8 data the absolute differences are in good agreement with the January 2003 values of 
Fig. 3, while CFC-11 ascending/descending differences of the modified L2 processing are much closer to zero. The improvement can well be seen in the relative differences. In $\mathrm{HNO}_{3}$ there is an advantage of data of the modified processing over V3O_HNO3_7 data above $100 \mathrm{hPa}$.

Altogether this means that already the inclusion of an appropriate external horizontal temperature gradient in a 1-D retrieval attenuates the ascending/descending differences.

This does not imply that the temperature field inhomogeneities are the only cause for deviations of 1-D retrieved vmr profiles from true atmospheric state, as it is known that inhomogeneities in the species vmr fields might well cause significant deviations too (Swartz et al., 2006). However, for mid IR limb sounding the temperature profile is a key quantity with strong influence on all species retrievals, which makes it so important to know this quantity as accurate as possible.

\section{Conclusions}

To sum up our conclusions with respect to the phenomenon's cause, impact and implications:

1. For several species there is a difference in 1-D retrieval species' profiles between ascending and descending parts of the orbit, which is not explainable in terms of chemistry or dynamics. For some species monthly means of relative differences in certain regions can reach $20 \%$ in the lower stratosphere.

2. Data from a 2-D retrieval do not show a corresponding systematic behaviour.

3. The pattern of the differences with respect to altitude and latitude implies that there is a combined effect of temperature gradient along MIPAS' line of sight which, for the same meridional temperature gradient, changes sign between ascending and descending orbit parts - and the species' vertical gradient.

4. A simple correction strategy, namely the consideration of prescribed horizontal temperature gradients in the forward calculations of the 1-D retrievals, appropriate for time and location of the measurements, significantly reduces the ascending/descending differences for a test data set of nine days.

There are two options to deal with the problem:

1. Passive approach: for data of 1-D processors a thorough error characterization including effects of temperature field inhomogeneities will be necessary.

2. Active approach: data processing should be carried out with processors capable of fully handling inhomogeneities (such as the GMTR, Carlotti et al., 2006) or at least those of the temperature field in the atmosphere (such as the gradient inclusion strategy employed in this study).

Implications for the users of MIPAS data of 1-D L2 processors are:

1. In any work using profiles of MIPAS 1-D retrievals it has to be verified whether the phenomenon demonstrated in this paper has to be taken into account. This can be done with help of the compilation of figures given in the electronic supplement to this paper.

2. Validation work should consider biases owing to ascending/descending differences.

3. Averages of 1-D data should best be calculated by first averaging profiles of ascending and descending orbit parts separately and averaging the two average profiles then. The latter average has to be performed without weighting by the number of profiles which entered the ascending/descending averages. Standard deviations estimated from both ascending and descending orbit parts together will be severely affected by the retrieval errors described in this paper.

4. Since we have found ascending/descending differences of a certain extent in monthly means, we can not exclude that single profiles or even averages of only few profiles will show larger deviations. This can be expected to occur in atmospheric situations with very strong horizontal temperature inhomogeneities, e.g. at the polar vortex boundary.

One must be aware that 1-D retrieval from measurements of other mid infrared limb emission sounders might also be affected by the effects described here when there are temperature gradients along the line of sight. The same conclusions as above are likely to hold for these instruments with respect to their 1-D L2 processors too.

\section{Supplementary material related to this article is available online at: http://www.atmos-meas-tech.net/3/1487/2010/ amt-3-1487-2010-supplement.pdf.}

Acknowledgements. Enrico Arnone acknowledges funding through the European Community's Human Potential Programme Marie Curie under contract MERG-CT-2007-209157. Enzo Papandrea acknowledges support by ESA within the framework of the Changing Earth Science Network Initiative. Fabrizio Niro (Serco) and Thorsten Fehr (ESA/ESRIN) have provided data and documents. The retrievals of IMK/IAA were performed partly on the HP XC4000 of the Scientific Supercomputing Center (SSC) Karlsruhe under project grant MIPAS. Last but not least we want to thank the two anonymous referees, whose comments helped to significantly improve the lucidity of the text.

Edited by: E. Kyrölä 


\section{References}

Bernath, P.: Atmospheric Chemistry Experiment, in Optical Remote Sensing of the Atmosphere, OSA Technical Digest, p. 22, Optical Society of America, Washington, DC, 1999.

Bernath, P. F., McElroy, C. T., Abrams, M. C., Boone, C. D., Butler, M., Camy-Peyret, C., Carleer, M., Clerbaux, C., Coheur, P.F., Colin, R., DeCola, P., De Mazière, M., Drummond, J. R., Dufour, D., Evans, W. F. J., Fast, H., Fussen, D., Gilbert, K., Jennings, D. E., Llewellyn, E. J., Lowe, R. P., Mahieu, E., McConnell, J. C., McHugh, M., McLeod, S. D., Michaud, R., Midwinter, C., Nassar, R., Nichitiu, F., Nowlan, C., Rinsland, C. P., Rochon, Y. J., Rowlands, N., Semeniuk, K., Simon, P., Skelton, R., Sloan, J. J., Soucy, M.-A., Strong, K., Tremblay, P., Turnbull, D., Walker, K. A., Walkty, I., Wardle, D. A., Wehrle, V., Zander, R., and Zou, J.: Atmospheric Chemistry Experiment (ACE): Mission overview, Geophys. Res. Lett., 32, L15S01, doi:10.1029/2005GL022386, 2005.

Brasseur, G. and Solomon, S.: Aeronomy of the Middle Atmosphere-Chemistry and Physics of the Stratosphere and Mesosphere, Atmospheric and Oceanographic Sciences Library 32, Springer, P. O. Box 17, 3300 AA Dordrecht, The Netherlands, third edn., 2005.

Carlotti, M.: Global-fit approach to the analysis of limb-scanning atmospheric measurements, Appl. Opt., 27, 3250-3254, 1988.

Carlotti, M., Dinelli, B. M., Raspollini, P., and Ridolfi, M.: Geofit approach to the analysis of limb-scanning satellite measurements, Appl. Opt., 40, 1872-1885, 2001.

Carlotti, M., Brizzi, G., Papandrea, E., Prevedelli, M., Ridolfi, M., Dinelli, B. M., and Magnani, L.: GMTR: Two-dimensional geofit multitarget retrieval model for Michelson Interferometer for Passive Atmospheric Sounding/Environmental Satellite observations, Appl. Opt., 45, 716-727, 2006.

Carlotti, M., Dinelli, B. M., Papandrea, E., and Ridolfi, M.: Assessment of the horizontal resolution of retrieval products derived from MIPAS observations, Opt. Express, 15, 10458-10472, 2007.

Dinelli, B. M., Alpaslan, D., Carlotti, M., Magnani, L., and Ridolfi, M.: Multi-target retrieval (MTR): the simultaneous retrieval of pressure, temperature and volume mixing ratio profiles from limb-scanning atmospheric measurements, J. Quant. Spectrosc. Radiat. Transfer, 84, 141-157, 2004.

Dinelli, B. M., Arnone, E., Brizzi, G., Carlotti, M., Castelli, E., Magnani, L., Papandrea, E., Prevedelli, M., and Ridolfi, M.: The MIPAS2D database of MIPAS/ENVISAT measurements retrieved with a multi-target 2-dimensional tomographic approach, Atmos. Meas. Tech., 3, 355-374, doi:10.5194/amt-3-355-2010, 2010.

Dudhia, A., Jay, V. L., and Rodgers, C. D.: Microwindow selection for high-spectral-resolution sounders, Appl. Opt., 41, 36653673, 2002.

Fischer, H., Blom, C., Oelhaf, H., Carli, B., Carlotti, M., Delbouille, L., Ehhalt, D., Flaud, J.-M., Isaksen, I., López-Puertas, M., McElroy, C. T., and Zander, R.: Envisat-MIPAS, an instrument for atmospheric chemistry and climate research, European Space Agency-Report SP-1229, edited by: Readings, C. and Harris, R. A., ESA Publications Division, ESTEC, P.O. Box 299, 2200 AG Noordwijk, The Netherlands, 2000.

Fischer, H., Birk, M., Blom, C., Carli, B., Carlotti, M., von Clarmann, T., Delbouille, L., Dudhia, A., Ehhalt, D., Endemann, M.,
Flaud, J. M., Gessner, R., Kleinert, A., Koopman, R., Langen, J., López-Puertas, M., Mosner, P., Nett, H., Oelhaf, H., Perron, G., Remedios, J., Ridolfi, M., Stiller, G., and Zander, R.: MIPAS: an instrument for atmospheric and climate research, Atmos. Chem. Phys., 8, 2151-2188, doi:10.5194/acp-8-2151-2008, 2008.

Funke, B., López-Puertas, M., García-Comas, M., Stiller, G. P., von Clarmann, T., Höpfner, M., Glatthor, N., Grabowski, U., Kellmann, S., and Linden, A.: Carbon monoxide distributions from the upper troposphere to the mesosphere inferred from $4.7 \mu \mathrm{m}$ non-local thermal equilibrium emissions measured by MIPAS on Envisat, Atmos. Chem. Phys., 9, 2387-2411, doi:10.5194/acp-92387-2009, 2009.

Höpfner, M., von Clarmann, T., Engelhardt, M., Fischer, H., Funke, B., Glatthor, N., Grabowski, U., Kellmann, S., Kiefer, M., Linden, A., López-Puertas, M., Milz, M., Steck, T., Stiller, G. P., Wang, D. Y., Ruhnke, R., Kouker, W., Reddmann, T., Bernath, P., Boone, C., and Walker, K. A.: Comparison between ACEFTS and MIPAS IMK/IAA profiles of $\mathrm{O}_{3}, \mathrm{H}_{2} \mathrm{O}, \mathrm{N}_{2} \mathrm{O}, \mathrm{CH}_{4}$, CFC-11, CFC-12, $\mathrm{HNO}_{3}, \mathrm{ClONO}_{2}, \mathrm{NO}_{2}, \mathrm{~N}_{2} \mathrm{O}_{5}, \mathrm{CO}$, and $\mathrm{SF}_{6}$ in February/March 2006, in Proc. Third Workshop on the Atmospheric Chemistry Validation of Envisat, (ACVE-3), 4-7 December, 2006, ESRIN, Frascati, Italy, vol. ESA SP-642, CD-ROM, ESA Publications Division, ESTEC, Postbus 299, 2200 AG Noordwijk, The Netherlands, 2007.

Kleinert, A., Aubertin, G., Perron, G., Birk, M., Wagner, G., Hase, F., Nett, H., and Poulin, R.: MIPAS Level 1B algorithms overview: operational processing and characterization, Atmos. Chem. Phys., 7, 1395-1406, doi:10.5194/acp-7-13952007, 2007.

Livesey, N. J. and Read, W. G.: Direct retrieval of line-of-sight atmospheric structure from limb sounding observations, Geophys. Res. Lett., 27, 891-894, 2000.

Papandrea, E., Arnone, E., Brizzi, G., Carlotti, M., Castelli, E., Dinelli, B. M., and Ridolfi, M.: Two-dimensional tomographic retrieval of MIPAS/ENVISAT measurements of ozone and related species, International Journal of Remote Sensing, 31, 477483, 2010.

Raspollini, P., Belotti, C., Burgess, A., Carli, B., Carlotti, M., Ceccherini, S., Dinelli, B. M., Dudhia, A., Flaud, J.-M., Funke, B., Höpfner, M., López-Puertas, M., Payne, V., Piccolo, C., Remedios, J. J., Ridolfi, M., and Spang, R.: MIPAS level 2 operational analysis, Atmos. Chem. Phys., 6, 5605-5630, doi:10.5194/acp6-5605-2006, 2006.

Remedios, J. J., Leigh, R. J., Waterfall, A. M., Moore, D. P., Sembhi, H., Parkes, I., Greenhough, J., Chipperfield, M.P., and Hauglustaine, D.: MIPAS reference atmospheres and comparisons to V4.61/V4.62 MIPAS level 2 geophysical data sets, Atmos. Chem. Phys. Discuss., 7, 9973-10017, doi:10.5194/acpd7-9973-2007, 2007.

Ridolfi, M., Carli, B., Carlotti, M., von Clarmann, T., Dinelli, B., Dudhia, A., Flaud, J.-M., Höpfner, M., Morris, P. E., Raspollini, P., Stiller, G., and Wells, R. J.: Optimized Forward and Retrieval Scheme for MIPAS Near-Real-Time Data Processing, Appl. Opt., 39, 1323-1340, 2000.

Rodgers, C. D.: Inverse Methods for Atmospheric Sounding: Theory and Practice, vol. 2 of Series on Atmospheric, Oceanic and Planetary Physics, edited by: Taylor, F. W., World Scientific, 2000.

Steck, T., Höpfner, M., von Clarmann, T., and Grabowski, U.: 
Tomographic retrieval of atmospheric parameters from infrared limb emission observations, Appl. Opt., 44, 3291-3301, 2005.

Stiller, G. P., von Clarmann, T., Funke, B., Glatthor, N., Hase, F., Höpfner, M., and Linden, A.: Sensitivity of trace gas abundances retrievals from infrared limb emission spectra to simplifying approximations in radiative transfer modelling, J. Quant. Spectrosc. Radiat. Transfer, 72, 249-280, 2002.

Swartz, W. H., Yee, J.-H., Randall, C. E., Shetter, R. E., Browell, E. V., Burris, J. F., McGee, T. J., and Avery, M. A.: Comparison of high-latitude line-of-sight ozone column density with derived ozone fields and the effects of horizontal inhomogeneity, Atmos. Chem. Phys., 6, 1843-1852, doi:10.5194/acp-6-1843-2006, 2006.

von Clarmann, T. and Echle, G.: Selection of optimized microwindows for atmospheric spectroscopy, Appl. Opt., 37, 7661-7669, 1998.

von Clarmann, T., Dudhia, A., Edwards, D. P., Funke, B., Höpfner, M., Kerridge, B., Kostsov, V., Linden, A., López-Puertas, M., and Timofeyev, Y. M.: Intercomparison of radiative transfer codes under non-local thermodynamic equilibrium conditions, J. Geophys. Res., 107, D22, 4631, doi:10.1029/2001JD001551, 2002.

von Clarmann, T., Ceccherini, S., Doicu, A., Dudhia, A., Funke, B., Grabowski, U., Hilgers, S., Jay, V., Linden, A., LópezPuertas, M., Martín-Torres, F.-J., Payne, V., Reburn, J., Ridolfi, M., Schreier, F., Schwarz, G., Siddans, R., and Steck, T.: A blind test retrieval experiment for infrared limb emission spectrometry, J. Geophys. Res., 108, D23, 4746, doi:10.1029/2003JD003835, 2003a. von Clarmann, T., Glatthor, N., Grabowski, U., Höpfner, M., Kellmann, S., Kiefer, M., Linden, A., Mengistu Tsidu, G., Milz, M., Steck, T., Stiller, G. P., Wang, D. Y., Fischer, H., Funke, B., GilLópez, S., and López-Puertas, M.: Retrieval of temperature and tangent altitude pointing from limb emission spectra recorded from space by the Michelson Interferometer for Passive Atmospheric Sounding (MIPAS), J. Geophys. Res., 108, D23, 4736, doi:10.1029/2003JD0036022003b.

von Clarmann, T., Höpfner, M., Funke, B., López-Puertas, M., Dudhia, A., Jay, V., Schreier, F., Ridolfi, M., Ceccherini, S., Kerridge, B. J., Reburn, J., and Siddans, R.: Modelling of atmospheric mid-infrared radiative transfer: the AMIL2DA algorithm intercomparison experiment, J. Quant. Spectrosc. Radiat. Transfer, 78, 381-407, 2003c.

von Clarmann, T., De Clercq, C., Ridolfi, M., Höpfner, M., and Lambert, J.-C.: The horizontal resolution of MIPAS, Atmos. Meas. Tech., 2, 47-54, doi:10.5194/amt-2-47-2009, 2009a.

von Clarmann, T., Höpfner, M., Kellmann, S., Linden, A., Chauhan, S., Funke, B., Grabowski, U., Glatthor, N., Kiefer, M., Schieferdecker, T., Stiller, G. P., and Versick, S.: Retrieval of temperature, $\mathrm{H}_{2} \mathrm{O}, \mathrm{O}_{3}, \mathrm{HNO}_{3}, \mathrm{CH}_{4}, \mathrm{~N}_{2} \mathrm{O}, \mathrm{ClONO}_{2}$ and $\mathrm{ClO}$ from MIPAS reduced resolution nominal mode limb emission measurements, Atmos. Meas. Tech., 2, 159-175, doi:10.5194/amt-2-1592009, 2009. 